NBER WORKING PAPER SERIES

\title{
BUSINESS LITERACY AND DEVELOPMENT: \\ EVIDENCE FROM A RANDOMIZED CONTROLLED TRIAL IN RURAL MEXICO
}

\author{
Gabriela Calderon \\ Jesse M. Cunha \\ Giacomo De Giorgi \\ Working Paper 19740 \\ http://www.nber.org/papers/w19740
}

\author{
NATIONAL BUREAU OF ECONOMIC RESEARCH \\ 1050 Massachusetts Avenue \\ Cambridge, MA 02138 \\ December 2013
}

We thank Shauna Cozad, Marina Kutyavina, Paul Feldman, and especially José Maria (Chema) Gardoni, Alejandro Maza, and Carla Roa for excellent research assistance. We are especially indebted to Leticia Jaraegui and the staff of CREA. Helpful comments were made by Pascaline Dupas, Rema Hanna, Dean Karlan, Asim Khwaja, Neale Mahoney, Anant Nyshandham, Jon Robinson, Mark Rosenzweig, Fabiano Schivardi, Chris Udry, and seminar participants at UCLA, Harvard-MIT, Yale, USC, Cal-Poly San Luis Obispo, NY-Fed, IFPRI, the IDB, and the EIEF. We gratefully acknowledge funding from Stanford Center for International Development, the Freeman Spogli Institute, the Michelle R. Clayman Insti- tute for Gender Research, the Social Science Research Council, the Graduate Research Opportunity (Studies and Diversity Program of the School of Humanities and Sciences, Stanford University), and SEED. Giacomo De Giorgi acknowledges financial support from the Spanish Ministry of Economy and Competitiveness, through the Severo Ochoa Programme for Centres of Excellence in R\&D (SEV2011-0075). The views expressed herein are those of the authors and do not necessarily reflect the views of the National Bureau of Economic Research.

NBER working papers are circulated for discussion and comment purposes. They have not been peerreviewed or been subject to the review by the NBER Board of Directors that accompanies official NBER publications.

(C) 2013 by Gabriela Calderon, Jesse M. Cunha, and Giacomo De Giorgi. All rights reserved. Short sections of text, not to exceed two paragraphs, may be quoted without explicit permission provided that full credit, including $(\mathcal{C}$ notice, is given to the source. 
Business Literacy and Development: Evidence from a Randomized Controlled Trial in Rural

Mexico

Gabriela Calderon, Jesse M. Cunha, and Giacomo De Giorgi

NBER Working Paper No. 19740

December 2013

JEL No. C93,I25,O12,O14

\begin{abstract}
A large share of the poor in developing countries run small enterprises, often earning low incomes. This paper explores whether the poor performance of businesses can be explained by a lack of basic business skills. We randomized the offer of a free, 48 -hour business skills course to female entrepreneurs in rural Mexico. We find that those assigned to treatment earn higher profits, have larger revenues, serve a greater number of clients, are more likely to use formal accounting techniques, and more likely to be registered with the government. Indirect treatment effects on those entrepreneurs randomizedlout of the program, yet living in treatment villages, are economically meaningful, yet imprecisely measured. We present a simple model of experience and learning that helps interpret our results, and consistent with the theoretical predictions, we find that "low-quality" entrepreneurs are the most likely to quitltheir business post-treatment, and that the positive impacts of the treatment are increasing in entrepreneurial quality.
\end{abstract}

Gabriela Calderon

\&HQNOOOOONRIDO H IFR

Ave. 5 de Mayo 2,

Centro, Cuauhtémoc, 06059

Ciudad[GH0 p[ IFRT LIMUR] HOHDO

$0 \mathrm{p}[\mathrm{IFR}]$

gabriela.calderon@banxico.org.mx

Jesse M. Cunha

Naval Postgraduate School

Graduate School of Business

and Public Policy

555 Dyer Rd

Monterey, CA 93943

jcunha@nps.edu
Giacomo De Giorgi

Departament d'Economia i d'Historia Economica

Edifici B, Office B3-1122

Universitat Autònoma de Barcelona

08193 Bellaterra, (Barcelona)

Spain

and NBER

giacomo.degiorgi@gmail.com 


\section{Introduction}

Self-employed, non-agricultural workers make up about 45 percent of the labor force in lower income countries, and private sector led growth is often stressed as an engine of creating jobs and spurring growth (World Development Report 2013). A persistent puzzle, however, is the observation that micro-entrepreneurs, females in particular, in developing countries often do not run their businesses efficiently; for example, through the misallocation of capital and labor in the firm (see Mckenzie and Woodruff (2012) for a review of this literature). Given the importance of entrepreneurship in the development process, especially amongst women, it is of utmost importance to understand both how business decisions are made and if poor decisions are caused by a lack of business literacy and managerial knowledge.

In response to this perceived underperformance of female entrepreneurs, a considerable number of NGOs around the world provide business training; however, there is yet little evidence that this type of intervention is needed or effective. Among economists, there is an increasing interest in understanding the links between the variation in firm profits and financial and managerial practices in developing countries (see de Mel, Mckenzie and Woodruff (2009a); Karlan and Valdivia (2011); and Bloom et al. (2013)). At the same time, more research is required to understand the way poor entrepreneurs make their investment decisions (de Mel, McKenzie and Woodruff, 2008).

In this paper, we analyze the effects of providing business training to small and micro female entrepreneurs through a Randomized Controlled Trial. The experiment was conducted in the poor, rural Mexican state of Zacatecas and includes about 900 entrepreneurs who are engaged in many different activities, such as making and selling food, making craft items, or selling consumer goods in small shops. A random subset of these entrepreneurs were offered a free, 48 -hour business training course which focused on simple business concepts, such as identifying unit costs, the importance of recording sales, and pricing to maximize profits, and emphasized the practical application of these concepts in the entrepreneurs' own business. Our research aims to answer two questions: (i) Is the policy intervention of classroom training effective at improving business outcomes? (ii) Can we shed light on the possible mechanisms through which the intervention worked?

In regards to the first question, we find that the offer of classes raises profits, revenues, and the number of clients served for those women who were invited to the treatment. We also find that the intervention led to an increase in the use of formal accounting techniques as well as an increase in the 
likelihood of formally registering with the government, which requires paying taxes but also allows firms to issue legal bills of sale. Treated firms were able to reduce their costs and change the mix of products they sold: specifically, they increased the number of items sold, dropping higher cost, lower price goods and adding lower cost higher price goods. Furthermore, we collected two rounds of postintervention data, one year and 2.5 years post-program implementation, and find that the effect of the treatment does not diminish into the medium run.

In order to shed light on the possible mechanisms driving our results, we develop a simple conceptual framework along the lines of Karlan, Knight and Udry (2012). We think of the entrepreneur in this context as an experimenter with a noisy signal of her productivity who faces the outside option of quitting her business. The offer of business classes lower the cost of (or introduce) a new, more expensive, yet potentially profitable, technology for running one's business, i.e., a set of new managerial and accounting practices. The entrepreneur then decides whether to adopt this more productive and expensive technology. However, the technology is risky, entrepreneurs are heterogeneous in their ability (or productivity), the technology is only profitable for those with high ability, and ability is only partially observable to the entrepreneur. Through the adoption of the new technology, irrespective of the outcome, the entrepreneur learns her own productivity which informs her decision about whether to continue running the business, and with which technology.

This model offers two testable implications: first, amongst treated entrepreneurs, the probability of quitting one's business should be higher for those with lower ability, and second, the effect of the treatment on profits should be higher for those with greater ability. Bringing these predictions to the data, and proxying for ability with the level of pre-treatment profits, we find that low ability entrepreneurs are indeed more likely to quit their businesses as a result of the training, and the largest positive effects are recorded amongst the "best" entrepreneurs.

A further contribution of our study is that the randomization was conducted at both the village and intra-village levels, which allows us to study spillover and general equilibrium effects on nonparticipants in program villages (Miguel and Kremer (2004); Angelucci and De Giorgi (2009)). It is unclear whether the indirect treatment effects should be positive or negative; for example, treated subjects may implement better business practices and capture market share at the expense of non-treated entrepreneurs, or, treated subjects may share their knowledge with non-treated subjects, intentionally through conversation or unintentionally if the new business practices are observable (such as new 
menus, changes to the product mix, or changes in prices). Regardless, it is clear that the presence or absence of indirect treatment effects have important implications for the global effectiveness of development policies.

In terms of profits, we detect negative, although not statistically significant, spillover effects of the treatment, which seem to arise from an increase in costs, and not from a fall in revenues. This result, together with the finding that treated firms face lower costs, suggests that the control and treated women purchase their inputs from different suppliers (which are more costly for the control group in treatment villages) or that suppliers have latitude to set differentiated prices. Combing the direct and indirect effects, a back-of-the-envelope cost and benefit analysis developed in Section 6 suggests that the intervention is extremely cost effective.

Our paper contributes to the growing literature on the effects of business literacy training on firms profitability. For example, empirical evidence is presented by Field, Jayachandran and Pande (2010) in India, Karlan and Valdivia (2011) and Valdivia (2011) in Perú, Drexler, Fischer and Schoar (2011) in the Dominican Republic, Berge, Bjorvatn and Tungodden (2011) in Tanzania, Bruhn and Zia (2011) in Bosnia-Herzegovina, and Giné and Mansuri (2011) in Pakistan, and Fairlie, Karlan and Zinman (2012) in the United States.

At the same time, our intervention is distinct from this literature in several important ways. First, the pedagogy focuses on the practical application of the skills and topics in the entrepreneurs' own businesses. Second, the training is intensive, with a total of 48 hours of classes over 6 weeks. Compared with other training programs, the course is relatively long and intensive; for example many programs associated with microfinance organizations last only 30 minutes, added on to weekly or monthly borrower meetings (Mckenzie and Woodruff (2012)). Third, the entrepreneurs in our sample do not receive any other treatment, for example, none are involved in micro-finance or other targeted business interventions. ${ }^{1}$ This last feature is important because it allows us to isolate the independent effect of business training, something that is not possible with much of the existing literature (e.g., Field, Jayachandran and Pande (2010), Karlan and Valdivia (2011), Drexler, Fischer and Schoar $(2011))^{2}$

Our paper also relates to the work of Nyshadham (2013), who provides theoretical arguments

\footnotetext{
${ }^{1}$ Only 4.5 percent of our sample had received a loan from a microfinance institution or the government in the previous 12 months.

${ }^{2}$ Indeed, de Mel, Mckenzie and Woodruff (2012) find substantial complementarities between business training and the availability of credit amongst female entrepreneurs in Sri Lanka.
} 
on the effects of business literacy training on entrepreneurial decision making, and to the growing literature on the effects of management services in developing countries (Bloom et al. (2013); Bruhn, Karlan and Schoar (2012); Karlan, Knight and Udry (2012)).

The remainder of the paper is as follows: Section 2 describes the business literacy training and our experimental design; Section 3 develops a conceptual framework to help interpret the main findings; Section 4 describes the data and the sample; 5 presents the empirical methodology and discusses the main effects of the intervention; and Section 6 concludes.

\section{Description of the Business Literacy Training and Experiment}

\subsection{The business literacy classes}

In 2009, we partnered with the NGO CREA to develop and implement a business literacy training program for small, female headed firms in the retail or production sector. CREA operates in small villages in the Mexican state of Zacatecas, a high-altitude, dry, and agricultural region. While there is good road access to all villages in which CREA operates, the inhabitants are none-the-less isolated in most of their daily activities as villages are geographically isolated, separated by farms and arid land.

The training program consists of two four-hour classroom meetings per week and runs for six weeks - a total classroom time of 48 hours. The classes are designed to be small and inclusive, with two instructors and a class size of no more than 25 entrepreneurs; all instructors are experienced local university professors, graduate, and undergraduates students. Furthermore, the program is free to invitees. In fact, CREA offers participants several incentives to further encourage participation, including: a completion certificate from CREA, the Institute for Women of Zacatecas (a government agency), and the Autonomous University of Zacatecas (the local university); in-class raffles for small prizes (e.g., a CREA hat or stationary supplies) each week conditional on attendance and homework completion; and the promise of acceptance in future CREA courses conditional on regular attendance.

The business literacy course covers six main topics, each taught in separate weekly modules. The first consists of understanding costs (e.g., the difference between unit, marginal, fixed, and total costs) and how they should be measured. The second covers how to optimally set prices. In this module, emphasis is placed on the concepts of profit maximization and pricing to reflect marginal costs, rather than average or fixed costs, as well as the concepts of demand and competition. The third module reviews the basic legal rights and obligations of small business owners. Since the vast majority of participants own informal businesses, this module includes a discussion of the costs and benefits of 
formally registering a business with the government. The fourth module covers general business organization and the choice of products to produce or sell. The fifth covers marketing, including concepts related to knowing and responding to competition. The final module is a discussion of how to be an effective salesperson.

The content and teaching style of CREA's course is intentionally simplified in order to be understandable to the population at hand, the majority of whom have low levels of formal education. As such, classes emphasize practical examples and encourage students to relate the concepts to their own businesses. For each module, students received a 30 page "textbook" which discusses (1) the importance of the concept, (2) the definition of the concept, (3) examples of how to compute or use the concept (e.g., how to do basic business accounting or compute unitary costs), (4) in-class exercises, and (5) exercises for homework. In-class instruction follows this structure, first introducing the main concepts, then applying those concepts to simple examples that are relevant to the participants' own businesses. $^{3}$

\subsection{Experimental design and population of study}

Our experimental design contains two-stages. In the first, villages were randomized into either treatment or control, and in the second, entrepreneurs within treatment villages were randomized to receive or not receive an invitation to attend the classes. This design allows us to estimate the direct effect of the program, by comparing invitees in treatment villages to entrepreneurs in control villages, as well as the indirect effects of the program, by comparing those not invited to attend classes in treatment village to entrepreneurs in control villages.

Working with CREA, we selected a sample of entrepreneurs by first choosing villages, and then conducting a census of the female entrepreneurs in those villages who produced or sold goods. Our original sample frame included all villages in the state of Zacatecas that met three criteria: that they (i) had between 100 and 500 female entrepreneurs who sold goods or provided services, as identified by the 2005 Mexican census, (ii) are within a two hour drive from the City of Zacatecas, and (iii) had less than 1500 households (also identified by the 2005 Mexican census). ${ }^{4}$ This selection process identified 25 villages. In order to accommodate our survey budget as well as CREAs institutional capacity, we randomly drew a sample of 17 villages from this set of 25 to be included in the study.

\footnotetext{
${ }^{3}$ An in-class example and exercise can be seen in Apendix Figure 1.

${ }^{4}$ The second criterion was necessary to ensure that the CREA instructors who lived in Zacatecas City would be able to reach treated villages.
} 
Within chosen villages, we identified female entrepreneurs that produced and/or sold goods with a modified snowball sampling technique as follows: First, we contacted the elected village leader (the comisario or presidente municipal, a mayor-like position) and asked him/her to introduce us to at least three knowledgable local women (the "seeds"). Second, we asked this group to list all of the women in the village that (i) work for themselves and (ii) sell a good. None of the local seed women were entrepreneurs themselves, and enumerators emphasized to the seed women the importance of identifying as close to a census of women entrepreneurs as possible. This process yielded about 50 female entrepreneurs per village, to whom we applied a pre-intervention questionnaire between July and September of 2009. ${ }^{5}$ We did not have the resources to survey male entrepreneurs, which limits our ability to estimate the full indirect effects of treatment (spillover and general equilibrium effects). However, our experience in these villages is that the majority of the goods that are sold by women are not also sold by men, in which case we would indeed be capturing the entire market. Importantly, none of the entrepreneurs we surveyed report selling their goods outside of their own village, suggesting it is unlikely that there are program spillovers across villages.

In order to assign subjects to treatment, we used information on business activity and demographics from the pre-treatment survey to perform the random assignment at both the village and intravillage levels. In early October 2009, eligible entrepreneurs were contacted in person by a CREA staff member informing them of their selection into the program. Classes began in late October and ran through December 2009, and attendance was recorded by the teachers.

\section{A Simple Model of Entrepreneurial Experimentation and Business Literacy}

To understand the potential effects of this intervention, we propose a simple theoretical framework which models entrepreneurs as experimenters with imperfect knowledge of their ability. This model is based on Karlan, Knight and Udry (2012) and captures two key components of our intervention: (i) accounting practices and (ii) "business" skills. At the same time, and differently from Karlan, Knight and Udry (2012) we allow for the outside option of quitting one's business.

Entrepreneurs are assumed to maximize their lifetime consumption subject to the resource constraint in the following programming problem:

\footnotetext{
${ }^{5}$ The remaining female entrepreneurs identified by the 2005 Mexican census were either in the service sector or were farmers who did not retail their produce.
} 


$$
\begin{aligned}
& \max _{c_{i t}} V \equiv E_{0} \sum_{0}^{\infty} \beta^{t} U\left(c_{i t}, w_{i}\right) \\
& \text { s.t. } \quad c_{i t} \leq \pi_{i t} \\
& \text { where } \pi_{i t}=f\left(x_{i}, \alpha_{i}\right)-x_{i} \text { and } \pi_{i 0}=w_{i}-x_{i}
\end{aligned}
$$

where $c_{i t}$ is entrepreneur $i$ 's consumption in period $t$ and $w$ is her initial wealth. We assume no credit markets are available, so consumption can not exceed per period profits $\pi_{i t}$. Revenues, $f\left(x_{i}, \alpha_{i}\right)$, are a function of the management technology the entrepreneur uses, $x_{i}$, and her productivity (i.e., her type), $\alpha_{i}$. Costs, also denoted by $x$, are indexed directly to the choice of management technology. The entrepreneur receives no revenue in the initial period $(t=0)$, yet must incur the cost of her choice of management technology in that period.

For simplicity, we assume that there are only two types of technology, new and old, denoted by $x_{h}$ and $x_{l}$ respectively, which cost $x_{h}$ and $x_{l}$ (with $x_{h}>x_{l}$ ). For the more productive types of entrepreneurs, the more expensive technology is more profitable than the less expensive technology, while for less productive types, the reverse is true: that is, $\pi_{i}\left(x_{h}\right)-x_{h}>\pi_{i}\left(x_{l}\right)-x_{l}$ only for entrepreneurs of above a certain productivity type, say, $\alpha^{h}$. If no management technology is chosen, the entrepreneur quits her business and incurs no cost, in which case $x_{i}=0$ and she receives the outside option pay-out $\pi_{i}^{0}$. As will become clear, we think of the business literacy classes as lowering the costs of, or introducing, the new management technology $\left(x_{h}\right)$ for those who attend the classes. ${ }^{6}$

Reflecting the environment in our experimental setting, we assume that the entrepreneurs do not know their type with certainty ex-ante, but believe they are either a high productivity type with probability $p_{i}^{h}$, a low productivity type with probability $p_{i}^{l}$, and very low productivity type (the type that will quit her business) with probability $p_{i}^{0}$, with $\sum_{j=0, l, h} p_{i}^{j}=1$. Choosing the new technology, however, will reveal the type of the entrepreneur ex-post as follows: if the more expensive management process succeeds, it returns $\pi_{i}^{h}$ and the entrepreneur knows she is of type $\alpha^{h}$ or greater; if it returns $\pi_{i}^{l}$ the entrepreneur knows she is of type $\left[\alpha^{l}, \alpha^{h}\right)$; and if it returns profits that are low enough, the very unsuccessful entrepreneur realizes that her type is lower than $\alpha^{l}$, and quits her business to receive the outside option, $\pi_{i}^{0}$. Thus, experimentation informs the entrepreneur whether she is: (i) a "good"; (ii)

\footnotetext{
${ }^{6}$ We assume that a non-empty set of entrepreneurs has sufficient initial wealth to experiment with the new technology if they so wish. Recall that there is no credit market available or alternatively that the technologies are not collateralizable.
} 
a "bad"; or (iii) a "non" entrepreneur.

The entrepreneur's value function is as follows:

$$
\begin{aligned}
V \equiv \max _{x=x^{l}, x^{h}, 0}=\quad & U(w-x)+ \\
& \mathbf{1}\left[x=x^{h}\right] \beta\left(p^{h} V\left(\pi^{h}\left(x^{h}\right), \alpha \geq \alpha^{h}\right)+p^{l} V\left(\pi^{l}\left(x^{h}\right), \alpha^{l} \leq \alpha<\alpha^{h}\right)+p^{0} V\left(\pi^{0}\left(x^{h}\right), \alpha<\alpha^{l}\right)\right)+ \\
& \mathbf{1}\left[x=x^{l}\right] \beta V\left(\pi^{l}, \alpha\right)+ \\
& \mathbf{1}[x=0] \beta V\left(\pi^{0}, \alpha<\alpha^{l}\right)
\end{aligned}
$$

The entrepreneur will decide to invest in the new technology rather than sticking with the old technology if the following condition holds:

$$
\begin{array}{r}
u\left(c^{l}\right)-u\left(w-x^{h}\right)<p^{h} \frac{\beta}{1-\beta} u\left(c^{h}\right)+\beta p^{l} u\left(\pi^{l}\left(x^{h}\right)\right)+\beta p^{0} u\left(\pi^{0}\left(x^{h}\right)\right)+ \\
p^{l} \frac{\beta^{2}}{1-\beta} u\left(c^{l}\right)+p^{0} \frac{\beta^{2}}{1-\beta} u\left(c^{0}\right)-\frac{\beta}{1-\beta} u\left(c^{l}\right)
\end{array}
$$

That is, she will choose to experiment if she is sufficiently optimistic about $p^{h}$. $^{7}$

Importantly, the new technology has a (positive) option value; that is, it offers the opportunity to learn one's type and possibly increase profits (become a "good" entrepreneur) if her type is high enough. Because of the positive option value, the entrepreneur may in fact choose to experiment even if the first-period expected (net) return from adopting the new technology is lower than the net return of the old technology, i.e. $p_{i}^{h} \pi_{i}^{h}\left(x^{h}\right)+p_{i}^{l} \pi_{i}^{l}\left(x^{h}\right)+p_{i}^{0} \pi_{i}^{0}\left(x^{h}\right)<\pi_{i}^{l}\left(x^{l}\right)$. The reason is that:

$$
u\left(c^{l}\right)-u\left(w-x^{h}\right)+\beta\left(u\left(c^{l}\right)-p^{h} u\left(c^{h}\right)-p^{l} u\left(\pi^{l}\left(x^{h}\right)\right)-p^{0} u\left(\pi^{0}\left(x^{h}\right)\right)\right)<p^{h} \frac{\beta^{2}}{1-\beta}\left(u\left(c^{h}\right)-u\left(c^{l}\right)\right) .
$$

The term on the left hand side is the option value. This relationship implies that even if the second term on the right hand side is positive and fairly large it could still be that the option value is large and positive.

\footnotetext{
${ }^{7}$ A similar problem applies to the decision of adopting the old technology, i.e., the decision to become an entrepreneur. We do not investigate this decision here as our baseline sample consists of entrepreneurs.
} 
Furthermore, if we maintain that high ability entrepreneurs are better off using the new technology, low ability entrepreneurs are better off sticking to the old technology, and the lowest ability types are best off by quitting, as follows:

$$
\begin{array}{r}
V\left(x^{0}, \alpha \leq \alpha^{l}\right)>V\left(x^{l}, \alpha \leq \alpha^{l}\right)>V\left(x^{h}, \alpha \leq \alpha^{l}\right) \\
V\left(x^{0}, \alpha>\alpha^{h}\right)<V\left(x^{l}, \alpha>\alpha^{h}\right)<V\left(x^{h}, \alpha>\alpha^{h}\right) \\
V\left(x^{l}, \alpha^{l}<\alpha \leq \alpha^{h}\right)>V\left(x^{h}, \alpha^{l}<\alpha \leq \alpha^{h}\right) \\
V\left(x^{l}, \alpha^{l}<\alpha \leq \alpha^{h}\right)>V\left(x^{0}, \alpha^{l}<\alpha \leq \alpha^{h}\right) .
\end{array}
$$

Then some entrepreneurs will quit their businesses when they discover their type. These ex-post choices can be summarized graphically for a given set of parameter values, as in Figure 2. It is clear that the value functions are ordered according to the above inequalities, implying that an entrepreneur would quit her business if her type is in the leftmost portion of the horizontal axis $(\alpha)$, she would employ the old technology for intermediate values of her type $(\alpha)$, and she would employ the new technology in the right part of the graph.

Under the assumption that the probability of success is positively related to one's ability, i.e. $p^{h}$ is positively related to $\alpha$, the treatment will induce less optimistic entrepreneurs to try the new technology relative to the control. This implies that the average difference between the treated and control groups in quit rates and profits cannot be signed ex-ante, as some of the treated are low ability types who are "trying out" the new technology. Thus, the average effect of the treatment (i.e., offering business literacy classes) is ambiguous on firm profits and quit rates, as we would require knowledge of the distribution of types and beliefs in the population, as well as the relative productivity gains the new technology offers. Ultimately, it is an empirical matter whether:

$$
\begin{array}{r}
\operatorname{Pr}(\text { Quit } \mid T=1)-\operatorname{Pr}(\text { Quit } \mid T=0) \gtreqless 0 \\
E(\pi \mid T=1)-E(\pi \mid T=0) \gtreqless 0,
\end{array}
$$

where $T=1$ for invited entrepreneurs in treatment villages, and 0 otherwise.

However, from the model, we do know that amongst the high ability entrepreneurs $\left(\alpha>\alpha^{h}\right)$, 
mean profits should increase amongst the treated relative to the controls:

$$
E\left(\pi \mid T=1, \alpha>\alpha^{h}\right)-E\left(\pi \mid T=0, \alpha>\alpha^{h}\right)>0 .
$$

Furthermore, we also know that amongst the low ability entrepreneurs $\left(\alpha \leq \alpha^{l}\right)$ we should see "excess" quitting amongst treatment group relative to the control group:

$$
\operatorname{Pr}\left(Q u i t \mid T=1, \alpha<\alpha^{l}\right)-\operatorname{Pr}\left(Q u i t \mid T=0, \alpha<\alpha^{l}\right)>0 .
$$

Testing these two predictions requires knowledge of $\alpha$. As we do not observe productivity directly, we proxy for productivity with pre-treatment profits, $\pi_{0}$. Thus, the two testable implications of this model are that the intention to treat effect on quitting should be non-increasing in pre-treatment profits and the intention to treat effect on profits should be non-decreasing in pre-treatment profits:

$$
\begin{array}{r}
\frac{\partial\{E(\pi \mid T=1)-E(\pi \mid T=0)\}}{\partial \pi_{0}} \geq 0 \\
\frac{\partial\{\operatorname{Pr}(\text { Quit } \mid T=1)-\operatorname{Pr}(\text { Quit } \mid T=0)\}}{\partial \pi_{0}} \leq 0 .
\end{array}
$$

In our empirical analysis below, we first explore the overall effects of the program and we then test these implications of this model of entrepreneurial decision making.

\section{Data and Sample}

\subsection{Data}

Our data includes an array of indicators of business performance, entrepreneurial ability, and socio-economic characteristics. In addition to the pre-intervention survey, two waves of data were collected post-intervention, approximately 18 months apart (the first between July and September 2010 and the second between March and May of 2012). These multiple post-intervention waves allow us to both analyze longer run impacts and increase the statistical power to detect significant program effects (McKenzie, 2012). All interviews were conducted by local enumerators with the stated purpose of studying female-run micro enterprises; intentionally, no connection was established with CREA or the intervention.

Our main measures of business performance include self-reports of profits, revenues, and the number of clients served, all from the last day the entrepreneur worked. Many women do not work 
the full week or regular hours; as such, they might be better able to remember daily figures rather than compute figures from a longer time horizon.

While evidence from other developing countries suggests that self-reported measures of aggregate business activity are as accurate as formal accounting figures (de Mel, Mckenzie and Woodruff, 2009b), we nonetheless also collected data on the individual goods sold in the enterprise at baseline and in the first followup. We first asked the entrepreneur to list all of the goods that she sold (up to a maximum of 14). ${ }^{8}$ We then asked for each good the number of units sold on the last day worked, the unit price, and the unit cost.

As the goods reported on in each survey round represent the contemporaneous stock of goods for sale, this data is an unbalanced panel at the good level. As such, it contains three types of goods: new goods for sale, old goods that were no longer sold, and goods that were sold both pre- and post-intervention. From this data, we first calculate aggregate measures of the stock of goods an entrepreneur sold, including total revenue, total profit, the total number of goods sold, and the meanacross-all-goods of both unit cost and price. These aggregate measures are useful because they capture optimizing decisions in terms of product stock, which could have been affected by the intervention; for example, a woman may learn that one product is losing money and drop that product; she may also decide to sell a new product with a larger profit margin. At the same time, this information provides a set of alternative measures of business performance which allows us to claim that non-classical measurement error is not the key to our findings.

We also use the good-specific data to examine how the product mix changes over time in response to the business training. Specifically, we examine treatment effects on total revenues, total profit, mean unit cost, and mean price amongst (i) the goods that the entrepreneur decided to stop selling (dropped goods), (ii) the goods that she continued to sell over both rounds (kept goods), and (iii) the goods she decided to start selling in the first post-intervention round (added goods).

Several other outcomes will give us further insight into how the intervention affects the performance of the business, including: the number of employees (both paid and unpaid), the number of co-owners, the average number of hours worked per week by the owner, and whether the entrepreneur is registered with the government agency in charge of collecting taxes and regulating business activity, the Secretary of Finance and Public Credit (Secretaria de Hacienda y Credito Publico, SCHP).

\footnotetext{
${ }^{8}$ Approximately six percent of the sample reported selling 14 goods; thus six percent of the sample could have had more than 14 different goods for sale, information which we do not capture.
} 
In order to directly examine the effect of the training classes on our subjects' business-math knowledge, we administered a simple exercise related to production and sales. ${ }^{9}$ This same question was applied both pre- and post-treatment. We score each of the four sections as either correct or incorrect, summing to create a total score for the exercise. Furthermore, we asked the entrepreneurs how they kept accounts for their business, whether through personal notes or a formal accounting method, or whether they did not keep any accounts.

To capture important heterogeneity in our sample pre-treatment, we also collected data on the owner's age, education, asset ownership (e.g. type of dwellings and number of rooms), risk aversion, reservation wages, credit availability and the cost of credit, the type of activity the woman is engaged in, the age of the business in months, and the size of business investments. Finally, in both postintervention surveys, we elicited a firm's survival by asking if the entrepreneur still sells any goods. Naturally, we do not observe these business-related outcomes for firms who quit their enterprise.

\subsection{Sample and summary statistics}

Our working sample includes 17 villages - seven treatment and ten pure control - and a total of 875 entrepreneurs: 164 eligible for and offered the treatment, 189 controls in treatment villages, and 522 in pure control villages. Figure 1 contains the distribution of the types of goods a firm sold, pre-intervention. The majority of firms (about 65 percent) were involved in the sale of food, either prepared (e.g., cheese, bread) or ready-to-eat (e.g., tacos, hamburgers, gorditas); general grocery store owners and other re-sale comprise a little over 25 percent of the sample; and handicrafts and clothing sum-up to about 10 percent.

Table 1 contains mean pre-intervention characteristics by treatment group, along with p-values from F-tests of their equality, and suggests that the randomization was successful in that the preintervention characteristics are for the most part indistinguishable across groups. For one variable, there is a significant difference across groups at the 5 percent level: more businesses were registered with the government in the control group than the treatment group.

This data paints a sobering picture of the economic lives of these entrepreneurs. Daily profits average around 140 pesos (approximately \$11 USD), with a large variation (the standard error of the mean is 16 pesos). ${ }^{10}$ Revenues are about four times the size of profits, and it is interesting to note this is the same order of magnitude as found amongst firms in Sri Lanka by de Mel, Mckenzie and

\footnotetext{
${ }^{9}$ This exercise can be seen in Appendix Figure 2.

${ }^{10}$ The dollar peso exchange rate in 2008-2009 was approximately 13 Mexican pesos to 1 U.S. dollar.
} 
Woodruff (2009b).

Business owners are on average 46 years old and have about six years of education. Approximately one third have a temporary roof on their residence (e.g., thatch or cardboard), an indirect measure of permanent income. Owners work for about 40 hours per week on average, and the total value of the capital stock (the replacement value of business capital) is about $\$ 570$. Interestingly, the entrepreneurs in our sample seem to have access to credit that would allow them to replace the business capital at a high (albeit common for this type of population) six percent monthly interest rate. ${ }^{11}$ Businesses are small: on average there are 1.6 workers including the owner, and employees work only about one quarter of the hours the owner works (about 10 hours per week). About 60 percent of businesses have no workers other than the owner. The average age of a firm is about seven years, again with large variation.

Importantly, the women in our sample know how to make basic calculations, but are less proficient at determining profits or optimally setting prices. For example, 93 percent said that they know how to make simple math calculations (not shown in the table), while the average score on the math exercise was 39 percent, or less than two out of the four questions answered correctly. ${ }^{12}$ Less than five percent of entrepreneurs (one percent in the treatment group and four percent in the control) keep formal business accounts, and only about one fifth of the sample is registered with the government.

\subsection{Take-up of classes}

Classes were offered to the selected invitees by a CREA staff member who visited the entrepreneur's home or business. Importantly, CREA made the intentional decision to not pre-screen invitees on the basis of the stated desire to accept the classes. As such, amongst the 164 entrepreneurs who were offered the classes, about 35 percent (57 entrepreneurs) did not attend any classes. Amongst those who did attend at least one class, an average of six classes were attended out of the 12 offered. Take-up and attendance rates are similar in magnitude to other business literacy interventions in the literature (Mckenzie and Woodruff, 2012).

Appendix Table 1 compares the mean pre-intervention characteristics of entrepreneurs who attended classes and those who did not, and shows that no variables are significantly different across groups at the five percent level. However, despite this lack of significant difference (partly driven by

\footnotetext{
${ }^{11}$ Replacement value of business capital was self-reported by the entrepreneur.

${ }^{12}$ Analyzing the questions of the math exercise separately, less than 50 percent could calculate profits correctly and only 18 percent could calculate the optimal price to set.
} 
the small sample size), attendees appear to be less successful entrepreneurs than non-attendees. For example, daily profits and revenues are about 50 percent higher for entrepreneurs who did not attend classes. Again, such findings are consistent with the literature (see, for example, Drexler, Fischer and Schoar (2011) and de Mel, Mckenzie and Woodruff (2012)).

In order to investigate the effect of treatment (being offered the class) on the treated (class attendees), we can instrument attendance status (which is presumably endogenous) with treatment status (which is exogenous due to randomization). However, for parsimony and a cleaner interpretation of the results, we instead focus on the Intent to Treat parameter to study the direct effect of the program, which compares eligible to ineligible entrepreneurs.

\subsection{Attrition}

Some entrepreneurs attrited from our sample between the baseline and the first and second followup surveys; importantly, however, attrition rates do not vary significantly across treatment groups (on average). Specifically, at the time of the first post-intervention survey, sample attrition was 12.8 percent in the treatment compared to 15.3 percent in the control $(\mathrm{p}$-value $=0.58)$. During the second followup survey, we were able to survey some of the attrited entrepreneurs from the first followup, while some new subjects attrited: relative to the baseline sample, attrition in the second followup was 16.5 percent in the control group compared to 18.3 percent in the treatment group ( $\mathrm{p}$-value $=0.77$ ). Virtually all of the attrited entrepreneurs either moved out of the village or were not available on the day of the interview; only three subjects ever refused to participate. ${ }^{13}$

\section{Empirical Strategy and Results}

To isolate the causal impact of the business training classes, we estimate a series of difference-indifferences models of the following form:

$$
y_{i t}=\alpha+\beta T_{i}+\delta \text { Post }_{t}+\gamma\left(T_{i} * \text { Post }_{t}\right)+\lambda \text { Wave }_{t}+\mathbf{X}_{\mathbf{i}} \Omega+\varepsilon_{i t}
$$

where $y$ is the outcome interest, $T$ is an indicator for living in a treatment village, Post is an in-

\footnotetext{
${ }^{13}$ Comparing entrepreneurs who ever attrited with those who did not reveals that, pre-intervention, attrited entrepreneurs have less education, have significantly lower revenues, employ fewer workers, and are less likely to produce goods rather than re-sell goods (see Appendix Table 2); these relationships hold equally in both the treatment and control groups (results available upon request).
} 
dicator for the post-intervention period, Wave $_{2}$ is an indicator for the first post-intervention survey, $\mathbf{X}$ is a vector of pre-intervention business and demographic characteristics, and $\varepsilon$ is an error term. Pre-intervention characteristics are included as covariates to increase precision, and we only include covariates that were used in the randomization algorithm; below, we demonstrate that results are robust to the exclusion of these controls. ${ }^{14}$

Several issues are of note: First, the direct effect of the offer of treatment, or the Intent to Treat (ITT) effect, is identified by $\gamma$ when equation 8 is estimated on the sample of all entrepreneurs in control villages and entrepreneurs in the treatment villages who were offered the classes (this identification strategy is immune from within-village spillover effects). The indirect effect of the offer of treatment, or the Indirect Treatment Effect (ITE), is identified by $\gamma$ when equation 8 is estimated on the sample of all entrepreneurs in the control villages and entrepreneurs in the treatment villages who were not offered the classes.

Second, with two post-intervention survey waves, we are able to estimate models that permit different treatment effects over time. However, as shown below, estimated treatment effects do not differ significantly across the two post-intervention survey waves, and so we pool the post-intervention surveys together in order to increase statistical power, while including Wave 2 to absorb any time-specific effects.

Finally, statistical inference is complicated by the small number of clusters (i.e., villages), implying that the standard (asymptotic) method for computing standard errors will be incorrect. We thus report both p-values representing asymptotic, clustered standard errors (at the village level) as well as p-values computed using the wild bootstrap of Cameron, Gelbach and Miller (2008). ${ }^{15}$

\subsection{The direct effect of classes on firm survival and main business related outcomes}

We first explore the effect of business literacy classes on firm survival. In each post-intervention survey wave, an entrepreneur was asked if she still runs her business, and we define a firm as quitting accordingly. Column 1 of Table 2 shows the ITT on the likelihood of quitting one's business is an insignificant 1.4 percentage points, suggesting that the offer of classes did not differentially induced

\footnotetext{
${ }^{14}$ These pre-intervention covariates include: the number of workers in the business; the age and sector of the enterprise; the replacement value of business capital; whether the entrepreneur states that she lacks business skills; whether she is risk averse; her age, education, and number of rooms in her home; and her score on the business skills exercise.

${ }^{15}$ Randomization inference (Rosenbaum, 2002) can also be used to construct hypothesis tests of treatment effects; however, because our treatment effects are large, the power of randomization inference can be low. Regardless, we have implemented permutation tests for a subset of outcomes, finding p-values that are similar in magnitude to wild bootstrap p-values.
} 
entrepreneurs to quit their business on average. However, many firms did quit their businesses over our survey period implying we do not observe business related outcomes (such as profits and revenues). Specifically, by the first and second followup surveys, 18.6 and 41.1 percent of the sample had stopped running their business respectively. ${ }^{16}$ This firm survival rate is small, but not abnormal for small businesses. For example, the five year survival rate for small businesses, of similar age to our sample, in the U.S. and other OECD countries is about 50-70\% (see Bartelsman, Scarpetta and Schivardi (2003) and U.S. Small Business Administration (2012)).

Columns 2-4 of Table 2 contain ITTs, estimated by equation 8 , for the logarithm of three main business outcomes: self-reported profits, revenues, and the number of clients served in the last day the entrepreneur worked. The ITT for the logarithm of last day's profits (column 2) is 0.215 , implying the offer of the business literacy classes has a positive effect on daily profits of about 23 percent. This effect is significant at the six percent level when using asymptotic, clustered standard errors and significant at the nine percent level when using wild bootstrapped, clustered standard errors. The corresponding Treatment on the Treated Effect (not reported) is larger by a factor of about 1.5 $(=1 / 0.65)$. This effect of business training on profits is large (both the ITT and the TTE), yet comparable to other studies in the literature (Bruhn, Karlan and Schoar (2012); Mckenzie and Woodruff (2012)).

Columns 3 and 4 of Table 2 show that treatment effects on revenues and the number of clients served are on the same order of magnitude as for profits - the ITT for revenues is 0.251 , significant at the five percent level with wild bootstrap p-values, while the ITT for clients served is 0.218 , significant at the 12 percent level with wild bootstrap p-values. It appears that the increase in revenues and the number of clients served is at least part of the explanation for the observed increase in profits; we return to probe these mechanisms in more detail below.

To address concerns with multiple hypothesis testing (Romano and Wolf, 2005), we create a standardized measure of the three main business outcomes presented in Table 2: profits, revenues, and clients served in the last day worked. As in Kling, Liebman and Katz (2007), we first standardize each of the variables independently with respect to the baseline control group and then take the average across the standardized measures. Column 5 of Table 2 shows that this standardized outcome

\footnotetext{
${ }^{16}$ Perhaps not surprisingly, there are significant differences between those who ever quit and those who did not (see Appendix Table 3); for example, compared to non-quitters, quitters were younger in age, worked fewer hours in their business, had fewer employees, and had been in business for less time. Furthermore, these relationships hold equally in both the treatment and control groups (results available upon request).
} 
increased by 0.154 standard deviations amongst those offered treatment, significant at the 5 percent level.

It is also important to note that the estimated treatment effects are of similar magnitude in both the short run (one year post-intervention) and the medium run (2.5 years after the intervention). Table 3 contains by-wave ITTs estimated from a version of equation 8 that includes indicators for each post-intervention wave, and their interaction with the treatment indicator. In general, point estimates of the ITT in wave 3 are of similar magnitude as in wave 2, yet are more noisy, and we can not reject the hypothesis that the ITTs are equal across waves. This latter result is rather important as it shows that the one time intervention appears to have long lasting positive effects which do not seem to decay 2.5 years after the intervention.

\subsection{Robustness of the main results}

Our estimated treatment effects are robust to various alternative specifications, as demonstrated in Table 4 for the main business outcomes. First, columns 1, 4, and 7 replicate the estimates in Table 2, but exclude pre-program covariates. Perhaps not surprisingly, given the randomization, the point estimates do not change meaningfully yet p-values increase as we lose precision. (While not shown in the table, the point estimate on quitting one's business also does not change meaningfully when covariates are excluded.)

Second, we test the robustness of the logarithmic transformation of the outcome when it equals zero in levels, i.e., when the entrepreneur has no revenue, no profit, or serves no clients. In columns 2, 5, and 8 of Table 4, we impute zero profits, revenues, and number of clients served with a small, strictly positive number (specifically, one peso of profit and revenue and 0.1 clients); again, point estimates and p-values are very similar to those in Table 2, suggesting that there is little information lost by excluding those observations with zero profits, revenues, or clients served in the logarithmic specifications.

Third, columns 3, 6, and 9 contain ITTs estimated using the level of the outcomes as opposed to the logarithm. While using the levels of these outcomes is not a preferred specification as their distributions are skewed, the magnitude and sign of the estimated ITTs are consistent with the logarithmic transformation. Specifically, the offer of business classes increased the last day's profits by 48.6 pesos, significant at the 10 percent level (wild bootstrap p-value); last day's revenues by an insignificant 65.2 pesos; and the number of clients served in the last day by an insignificant 1.6 clients. Finally, 
while the rates of attrition are not differential across treatment groups (see Section 4.4), we show in a final robustness check in Appendix A that our results are largely robust to potential differential attrition across treatment groups by applying Lee's Bounds (Lee, 2009).

\subsection{Possible mechanisms driving the main results}

Having established the large and significant effect of business literacy classes on business profits, we now turn to explore why these results arose. Two mechanisms were already presented in Table 2: self-reported revenues in the last day worked increased, as did the self-reported number of clients served in the last day worked. Our good-specific data provides a separate way to estimate treatment effects on profits and revenues, and ITTs for these outcomes are presented in the first two columns of Table 5. We find that the log of the mean good-specific profit and revenue increased by 16.6 and $23.7 \log$ points, respectively. Although insignificant at conventional significance levels, these point estimates are similar in magnitude to those for self-reported profits and revenues (and recall that we only observe these measures in the baseline and the first post-intervention surveys). ${ }^{17}$ Column 3 of Table 5 shows that entrepreneurs marginally increased the number of goods they sold as a result of the offer of classes: the ITT on the logarithm of the number of goods sold is 0.116 (approximately 1 extra good for sale), with a wild bootstrapped p-value of 0.155 . Interestingly, it appears that the observed increase in profits is coming from reduced costs rather than increased prices: the ITT for the logarithm of the mean unit cost of items sold is $-0.293 \log$ points (column 4, wild bootstrap p-value =7) while the ITT for the log of mean unit price is 0.004 (column 5, strongly insignificant).

It is also interesting to note that program invitees seem to be changing the composition of the goods they sell. In particular, Table 6 contains ITTs for the outcomes calculated from the goodspecific questionnaire, but restricts the sample to those goods that were either (i) dropped between the baseline and first post-intervention survey, (ii) kept across both surveys, or (iii) added in the first post-intervention survey. Although these results are somewhat only suggestive given the low-power of our tests at the good-by-good level, they suggest that entrepreneurs who were offered the treatment dropped goods with low profits, revenues, and prices; kept goods with high profits and revenues and low costs; and added goods with high revenues and low costs. This analysis suggests that our

\footnotetext{
${ }^{17}$ Having two measures of business profits and revenues - one self-reported and one calculated from the good specific data - allows us to test whether the extent of measurement error in these outcomes is systematically linked to the offer of classes. Specifically, we cannot reject the equality of the correlations in the two measures for either profits or revenues between the control and treatment groups in the ex-post period, nor in a difference-in-differences specification. These results are inconsistent with systematic measurement error being the main driver of the positive ITTs. We thank Rema Hanna for suggesting this testing strategy.
} 
entrepreneurs are endogenously changing their goods portfolio as a response to the business training, in a manner consistent improving their overall performance, and as taught in the classes.

Table 7 contains several other business related outcomes of interest. Column 1 presents the ITT on the percent of correct answers on the business practices exercise, and it seems that the program did not necessarily make entrepreneurs more business savvy, with a large but insignificant effect of 5.6 percentage points (on a pre-treatment mean of about 40 percent). However, it does appear that the offer of classes significantly and meaningfully increased the use of formal accounting practices: column 2 shows that 4.7 percentage points more entrepreneurs used formal accounting methods posttreatment (wild bootstrapped p-value $=0.07$ ). This is a large effect, considering that only one percent of treated entrepreneurs (and four percent of control entrepreneurs) used formal accounting practices pre-intervention. Although the effect is insignificant, the large point estimate on the number of hours worked per week by the owner (2.6 hours per week, column 3 ) is consistent with higher returns from entrepreneurship. There does not appear to be a significant effect of the program on the size of the enterprise, as measured by the number of employees (column 3), or on the number of hours worked per week by employees (column 4).

Finally, invitees are 8.6 percentage points more likely to register their business with a government agency (column 6); again, this is a large effect, representing an increase over pre-intervention registration levels of about 40 percent. The CREA course included a thorough discussion of the pros and cons of registering ones business, and this positive point estimate suggests that, upon learning this information, registering is an optimal decision for some entrepreneurs.

\subsection{Spillover and general equilibrium effects of business literacy classes}

We now turn to estimates of the Indirect Treatment Effects, estimated by equation 8 on the sample that excludes any entrepreneurs who were invited to the classes, and presented in Table 8 . To the extent that villages are segmented, these estimates identify the local spillover and general equilibrium effects of the intervention.

First, there is no evidence of a significant ITE on quitting one's business. Furthermore, it is clear that very few of ITEs on business related outmodes are in Table 8 are significantly different from zero. However, the magnitude of many of the estimates are large and economically meaningful. In particular, the ITE on the logarithm of self-reported last day's profit is negative and rather large in magnitude, implying a decrease in profits of about 11 percent for control entrepreneurs in treatment 
villages relative to entrepreneurs in control villages. This point estimate is about half of the increase in profits realized by treatment entrepreneurs in treatment villages (approximately 23 percent, Table 2), and suggests the overall effect of the program on the profits of female entrepreneurs in treatment villages is about 12 percent. ITEs on the last day's revenue and the number of clients are positive (just as the direct treatment effects), yet small in magnitude, approximately one quarter to one third the magnitude of the direct treatment effects. Not surprisingly given the opposing signs on the point estimates, the ITE on the standardized measure is essentially zero $(0.013$, wild bootstrap p-value $=$ $0.866)$.

Reassuringly, calculated profits and revenues from good-specific data yields very similar ITES to the self-reported measures, although these estimates are more precisely estimated (wild bootstrap p-values of 0.164 and 0.137 , respectively). There does not appear to be an indirect effect on the number of goods for sale, but the ITE on the logarithm of the mean unit cost is 0.221 and close to marginal significance (wild bootstrap p-value $=0.139$ ). Interestingly, this estimate is of similar magnitude to the direct effect (-0.293, Table 5), but of the opposite sign. It is not clear why these estimates should be so divergent, but perhaps if factor markets are not perfectly competitive, those offered treatment were able to purchase input materials from lower-cost suppliers, leaving those not offered the treatment to purchase inputs from higher-cost suppliers. It is theoretically ambiguous as to whether we would expect the indirect effect on prices of the control entrepreneurs to be positive or negative. The point estimate suggests a small, yet insignificant positive indirect effect of the treatment on the logarithm of the mean unit price $(0.072$, wild bootstrap p-value $=0.326)$.

It is reasonable to believe, given the small size of these villages, that treated entrepreneurs interact with non-treated entrepreneurs, perhaps sharing lessons learned in the business literacy classes. There do not appear to be spillover effects on business knowledge (as measured by our business practices exercise), but there does appear to be a large and statistically significant impact on the use of formal accounting methods: relative to the control villages, 5.7 percentage points more control entrepreneurs in treatment villages use formal accounting methods, significant at the 3 percent level (wild bootstrap p-value), however given their business outcomes the ineligibles don't seem to act upon the adoption of formal accounting or simply could not properly perform such formal accounting. This estimate is even larger than the positive direct effect of the treatment (a 4.7 percentage point increase, Table 7). However, unlike the direct effect, there is not a positive effect on the likelihood of being registered 
with the government; in fact, the ITE on this outcome is a negative 3.7 percentage points (wild bootstrap p-value $=0.337$.

There is not a significant indirect effect on the number of employees, but there is a significant increase in the hours worked by the owner (3.9 hours per week, an increase of about 10 percent over baseline) and a large-in-magnitude but slightly less significant increase in the hours worked by employees ( 2.3 hours per week, an increase of about 20 percent over baseline). Perhaps the untreated entrepreneurs in treatment villages have increased the hours worked in order to compensate for the decrease in profits (note that no entrepreneurs in our sample stated that they subtract the opportunity cost of their time from revenues in calculating profits).

\subsection{Testing the empirical predictions of the model of entrepreneurial experimentation}

The results presented above on the entire sample are useful for understanding the overall effect of the business training program. However, the model presented in section 3 offers further insight into how the program may differentially affect our entrepreneurs. In particular, the predictions are that the ITT on quitting should be non-increasing in pre-treatment profits and the ITT on profits should be non-decreasing in pre-treatment profits. We now test these predictions empirically. For ease of presentation, we split our sample into those above and below the median of the last day's pre-treatment profit, and present separate ITT $s$ estimated by equation 8 .

\section{Differential likelihood of quitting by baseline profits}

The first two columns of Table 9 speak to the prediction that entrepreneurs of lower ability should be more likely to quit their businesses upon trying the new management technologies taught in class. Lowering the cost of adopting this technology induces lower ability (lower $\alpha$ ) entrepreneurs to try the technology, and these "excessive" experimenters will rapidly realize they are not good entrepreneurs once they keep better accounting and try out different business practices. They therefore quit their enterprise. While not statistically significant, an economically meaningful differential in terms of quitting is apparent: column 1 of Table 9 shows that those below the median of pre-treatment profits are 1.9 percentage points more likely to quit while those above the median (column 2) are 4.8 percentage points less likely to quit, relative to the control. This differential (7.1 percentage points) is large, representing about 14 percent of the post-treatment quit rate amongst control firms.

We further explore the hypothesis that the treatment will induce the low ability entrepreneurs to quit by looking at the distribution of pre-treatment profits. First, we present the distributions of pre- 
treatment (baseline) profits in the whole sample compared to the distribution of pre-treatment profits amongst those who did not quit by the second followup survey: Figure 3 contains these distributions for the treatment and control group separately. It is clear that the survived sample (i.e., those who did not quit) is similar in terms of baseline profits to the whole sample in the control group. In the treatment group, however, the distribution of the survived sample is significantly shifted to the right consistent with the prediction that those with the lowest ability (pre-treatment profits) will be induced to quit upon learning they are in fact a low ability type. ${ }^{18}$

Second, we use a parametric framework to statistically test whether treated entrepreneurs in the far left tail of pre-treatment profits indeed have a high propensity to quit than similar control entrepreneurs. In the context of the model, the exercise we undertake amounts to searching for where $\alpha^{l}$ is located within the distribution of baseline profits. In practice, we conduct a grid search over percentiles of the distribution of baseline profits by regressing an indicator for quitting by the second followup survey on a treatment indicator, an indictor for being a given percentile of the last day's profits pre-treatment, and the interaction of these two indicators. Columns 1-3 of Table 10 shows the results of this exercise for the 1st, 3rd, and 5th lowest percentiles of pre-treatment profits. The interaction term is large and significant for the 1st and 3rd percentiles, and smaller in magnitude and insignificant for the 5th percentile. Thus, it appears $\alpha^{l}$ is around the 3rd percentile of pre-treatment profits, and the quit rate for treatment entrepreneurs in this lower 3 percentiles is 35.4 percentage points higher than the control. (Interaction terms for all percentiles greater than 5 are insignificant.) Furthermore, if we consider that attrition is a possible result of treatment, we can define successful businesses as those that did not quit or attrited by the second followup survey. Columns 4-6 of Table 10 present results of this exercise using this outcome and it is clear results are similar in magnitude (naturally, with the opposite sign) to those presented above. A further test of the model intuition on the effect of learning one's ability on quitting is that the $I T E^{\prime} s$ for quitting and attrition are essentially zero, consistently with a learning story. While if the mechanism at work were to be one of enhanced competition between firms in a given village we should see higher exits in control firms in treatment villages than in control villages, while that is not the case empirically.

\footnotetext{
${ }^{18}$ Kolmogorov-Smirnov tests for the equality of the distribution functions in Figure 3 yield p-values of 0.07 in the treatment group and 0.97 in the control group.
} 


\section{Differential effects on profits by baseline profits}

The remainder of Table 9 speaks to the second prediction of the model, that the treatment effect on profits should be increasing in the ability of the entrepreneur. Comparing ITTs in the samples above and below the median of pre-treatment profits, we see quite striking differences: by-and-large the positive effects of the intervention consistently arise from those above the median of pre-treatment profits. Although we cannot reject the equality of the effects between the top and bottom half of the baseline profits distribution, it is clear that the point estimates are economically quite different from each other, and the ITTs are only statistically different from zero amongst those above the median of pre-treatment profits. For example, the ITT on last day's profits is 0.254 for those above the median and 0.053 for those below the median.

A similar, albeit less statistically precise, story emerges when we look at the outcomes constructed from the good-specifc data in Table 11. While none of these estimates are significantly different from zero at more than the five percent level, point estimates suggest economically meaningful differential impact consistent with the predictions of our model. Specifically, last day's profits increased by $34.3 \log$ points for those above the median and fell by $11.2 \log$ points for those below the median. Similarly, treatment effects on the last day's revenues and the number of goods for sale are larger in magnitude for those above the median than for those below. Mean unit cost appears to have fell for both those above and below the median of pre-treatment profits, while the null overall effect on the mean unit price is masked by a slight increase in price amongst those above the median and a slight decrease for those below the median.

Finally, Table 12 shows another striking result: the positive treatment effect on the use of formal accounting practices is concentrated completely amongst the most able entrepreneurs: the ITT for those above the median of pre-treatment profits is 0.09 compared to 0.007 for those below the median, although neither of these estimates are significantly different from zero. There is a small differential in terms of knowledge gains as measured by our business practices exercise, no differential in terms of hours worked per week by the owner, but a large differential in terms of hours worked per week by employees: close to a 6 hour increase for those above the median compared to a 5 hour decrease for those below the median. These effects on hours worked by employees seem to be driven by differential hiring practices. There is little differential effect in terms of registering with the government.

Conscious of the fact that treatment effects are by-and-large not statistically distinguishable be- 
tween those with high and low ability (e.g., above and below the median of pre-treatment profits), the economically large differences in point estimates for many business-related measures lends support to the predictions of our theoretical model.

\section{Conclusions}

A large literature on enterprises in developing countries finds that firms are often run inefficiently (see for example Bloom et al. (2013); Bruhn, Karlan and Schoar (2012)), this could have multiple causes from the lack of credit market, to goods market imperfections and so on. Amongst those reasons it could be that entrepreneurs lack the basic business skills required to run an enterprise, such as an understanding of costs, sales, profits, price setting, marketing, and competition.

Recent years have seen a series of interventions offering business or financial training to entrepreneurs. Our intervention is unique in several ways, and thus offers new insights into our understanding of the effect of business literacy classes on enterprise performance. First, the intervention is very intensive, lasting six weeks with two, four-hour classes per week for a total instruction time of 48 hours; this is more than double many of the prior studies in this literature (e.g., Drexler, Fischer and Schoar (2011) and Karlan and Valdivia (2011). Second, our experimental design involves offering classes to a random subset of the population of micro-enterprises while not providing any other intervention (such as credit) beside business literacy training. This implies our findings are valid for a broad class of businesses, and identify the effects of the classes uniquely. Third, our survey design includes two post-intervention surveys (one year and 2.5 years post-intervention), which allows us to explore both the short and medium run effects of the training. Fourth, we are able to detect village-level spillover and general equilibrium effects thanks to our experimental design.

Our results indicate that a basic training in business management and accounting is capable of significantly increasing profits. This increase appears to be driven by a combination of higher revenues, lower costs, more clients served, and an increased use of formal accounting methods. Importantly, knowledge gained through the intervention does not appear to fade, as we observe positive effects persisting into the medium run.

These positive program impacts, however, must be weighed against the costs of running the business literacy classes in order to justify the intervention. In fact, a simple comparison of costs and benefits shows the program is indeed very cost-effective. First, the cost of running the CREA classes is extremely low, as local teachers were hired for a modest wage, minimal materials were provided to 
the students, and community centers were used to hold classes at no-cost. Specifically (and using US dollars for convenience), each of seven treatment villages had two teachers who taught for a total of 48 hours and were paid $\$ 10$ per hour yielding $\$ 6720$ ( $=7 \times 2 \times 48$ x $\$ 10)$ in salaries. While only 65 percent of invitees came to class, the classrooms would have accommodated all invitees, so if CREA were to replicate the program, the appropriate per-invitee cost of teacher's salaries with 164 invitees is $\$ 49.97$ (=\$6720 / 164). Materials (photocopies of lessons, pens, paper, calculators, and CREA logo hats that were used as prizes) totaled about $\$ 5$ per participant; inflating the latter costs to the invitees, the total per-invitee cost of CREA's program is $\$ 57.66(=\$ 49.97+\$ 7.79)$.

Second, a back-of-the-envelope calculation shows that the benefits in terms of increased profits far outweigh these costs: The ITT on the logarithm of daily profits is 0.215 , which implies the offer of classes increased daily profits by 23.4 percent $(=\exp (0.215))$. The mean pre-treatment daily profit in the treatment group was $\$ 10.2$, implying the offer of treatment increased daily profits by $\$ 2.38$ $(=\$ 10.2 \times 23.4 \%)$. Pre-treatment, entrepreneurs in the treatment group reported working an average of 5.17 days per week. We do not know how many weeks are worked per year, but given that some of the businesses are seasonal (such as selling certain handicrafts or seasonal foods), a conservative assumption is that the average entrepreneur works half the year, or 26 weeks. Using a seven percent annual discount rate, the present discounted value of the increased profits due to the program is $\$ 4394.50(=(\$ 2.38 \times 5.17 \times 26) / 0.07)$. It should be clear that it would be difficult to find a scenario under which increased profits do not outweigh the program costs, even if we were to include the opportunity cost of missed work when taking the classes, or to count as a program cost the negative indirect treatment effect on the profits of control firms in treatment villages.

Furthermore, our results are consistent with the predictions derived from our simple model of entrepreneurial experimentation: that only high-quality entrepreneurs will benefit from the business training, while very low quality entrepreneurs quit their business once the training helps them realize they are ill-suited to entrepreneurship. This is an important result which might have important longrun implications in terms of firm and market dynamics, in particular if bad firms have negative effects on potentially good firms, e.g. pricing below cost. For example, the faster disappearance of bad firms might allow good firms to grow to a scale that is more efficient (Hsieh and Klenow (2009) and Hsieh and Klenow (2010)).

Finally, an important finding is that the large positive direct effect of the program on firm profits 
is mitigated by a large negative (albeit imprecisely estimated) indirect effect on the profits of control firms in treatment villages. The negative indirect effect seems to arise from input market imperfections so that if the policy were to be scaled up it would not necessarily have negative spillover effects as long as there are enough suppliers of intermediate-production inputs. Estimated indirect treatment effects do not suggest a large effect on the demand side for the untreated entrepreneurs in the treatment villages, therefore if the policy were to be scaled up, as long as suppliers do not react increasing prices, we should expect effects of similar magnitudes to the one estimated here. Also notice that the increase in profits for treated firms comes only partially from savings on production costs, while about 50 percent of the effect is explained by changes in managerial practices and changes in the menu of goods. Several open questions remain for future research, including: Why is the supply market imperfect? Is there an alternative policy which would increase competition amongst suppliers and therefore reduce production costs? 


\section{References}

Angelucci, Manuela, and Giacomo De Giorgi. 2009. "Indirect Effects of an Aid Program: How Do Cash Transfers Affect Ineligibles' Consumption?” American Economic Review, 99(1): 486-508.

Bartelsman, Eric, Stefano Scarpetta, and Fabiano Schivardi. 2003. "Comparative Analysis of Firm Demographics and Survival: Micro-Level Evidence for the OECD Countries.” OECD Publishing OECD Economics Department Working Papers 348.

Berge, Lars Ivar, Kjetil Bjorvatn, and Bertil Tungodden. 2011. "Human and financial capital for microenterprise development: Evidence from a field and lab experiment." NHH Dept. of Economics Discussion Paper, , (1).

Bloom, Nicholas, Benn Eifert, Aprajit Mahajan, David McKenzie, and John Roberts. 2013. "Does management matter? Evidence from India." The Quarterly Journal of Economics, 128(1): 151.

Bruhn, Miriam, and Bilal Zia. 2011. "Stimulating Managerial Capital in Emerging Markets: The Impact of Business and Financial Literacy for Young Entrepreneurs." The World Bank, Policy research Working Paper.

Bruhn, Miriam, Dean S Karlan, and Antoinette Schoar. 2012. "The impact of consulting services on small and medium enterprises: Evidence from a randomized trial in mexico." Yale University Economic Growth Center Discussion Paper, , (1010).

Cameron, A Colin, Jonah B Gelbach, and Douglas L Miller. 2008. "Bootstrap-based improvements for inference with clustered errors." The Review of Economics and Statistics, 90(3): 414427.

de Mel, Suresh, David J. McKenzie, and Christopher Woodruff. 2008. "Returns to Capital in Microenterprises: Evidence from a Field Experiment." Quarterly Journal of Economics, 123(4): 1329-1372.

de Mel, Suresh, David J. Mckenzie, and Christopher Woodruff. 2009a. "Are Women more credit Constrained? Experimental Evidence on Gender and Microenterprise Returns." AEJ, Applied Economics, 1(3): 1-32.

de Mel, Suresh, David J. Mckenzie, and Christopher Woodruff. 2009b. "Measuring Microenterprise Profits: Must We Ask How the Sausage is Made?" Journal of Development Economics, 88(1): 19-31.

de Mel, Suresh, David J. Mckenzie, and Christopher Woodruff. 2012. "Business Training and Female Enterprise Start-up, Growth, and Dynamics Experimental evidence from Sri Lanka.” Mimeo.

Drexler, Alejandro, Greg Fischer, and Antoinette Schoar. 2011. "Keeping it Simple: Financial Literacy and Rules of Thumb.” Mimeo, MIT.

Fairlie, Robert, Dean Karlan, and Jonathan Zinman. 2012. "Behind the GATE Experiment: Evidence on Effects of and Rationales for Subsidized Entrepreneurship Training." NBER-WP, , (17804). 
Field, Erica, Seema Jayachandran, and Rohini Pande. 2010. "Do Traditional Institutions Constrain Female Entrepreneurship? A Field Experiment on Business Training in India.” The American Economic Review P\&P, 100(2): 125-129.

Giné, Xavier, and Ghazala Mansuri. 2011. "Money or Ideas? A Field Experiment on Constraints to Entrepreneurship in Rural Pakistan.” Mimeo.

Hsieh, Chang-Tai, and Peter J Klenow. 2009. "Misallocation and manufacturing TFP in China and India." The Quarterly Journal of Economics, 124(4): 1403-1448.

Hsieh, Chang-Tai, and Peter J Klenow. 2010. "Development accounting." American Economic Journal: Macroeconomics, 2(1): 207-223.

Karlan, Dean, and Martin Valdivia. 2011. "Teaching Entrepreneurship Impact of Business Training on Microfinance Clients and Institutions." The Review of Economics and Statistics, 93(2): 520-527.

Karlan, Dean, Ryan Knight, and Christopher Udry. 2012. "Hoping to win, expected to lose: Theory and lessons on micro enterprise development." National Bureau of Economic Research.

Kling, Jeffrey R., Jeffrey B. Liebman, and Lawrence F. Katz. 2007. "Experimental Analysis of Neighborhood Effects." Econometrica, 75(1): pp. 83-119.

Lee, David S. 2009. “Training, Wages, and Sample Selection: Estimating Sharp Bounds on Treatment Effects." The Review of Economic Studies, 76(3): pp. 1071-1102.

McKenzie, David. 2012. "Beyond baseline and follow-up: The case for more T in experiments." Journal of Development Economics, 99(2): 210-221.

Mckenzie, David, and Christopher Woodruff. 2012. "What are we learning from business training and entrepreneurship evaluations around the developing world?" The World Bank Policy Research Working Paper Series 6202.

Miguel, Edward, and Michael Kremer. 2004. "Worms: Identifying Impacts On Education And Health In The Presence Of Treatment Externalities.” Econometrica, 72(1): 159-217.

Nyshadham, Anant. 2013. "Learning about Comparative Advantage in Entrepreneurhsip: Evidence from Thailand." working paper.

Romano, Joseph P., and Michael Wolf. 2005. "Stepwise Multiple Testing as Formalized Data Snooping." Econometrica, 73(4): pp. 1237-1282.

Rosenbaum, Paul. 2002. "Covariance Adjustment in Randomized Experiments and Observational Studies.” Statistical Science, 17(3): 286-327.

U.S. Small Business Administration. 2012. "Frequently Asked Questions about Small Businesses." Office of Advocacy, September, 2012.

Valdivia, Martin. 2011. "Training or Technical Assistance? A Field Experiment to Learn What Works to Increase Managerial Capital for Female Microentrepreneurs.” Unpublished. 
Figure 1: Sectors of micro-enterprise activity pre-treatment

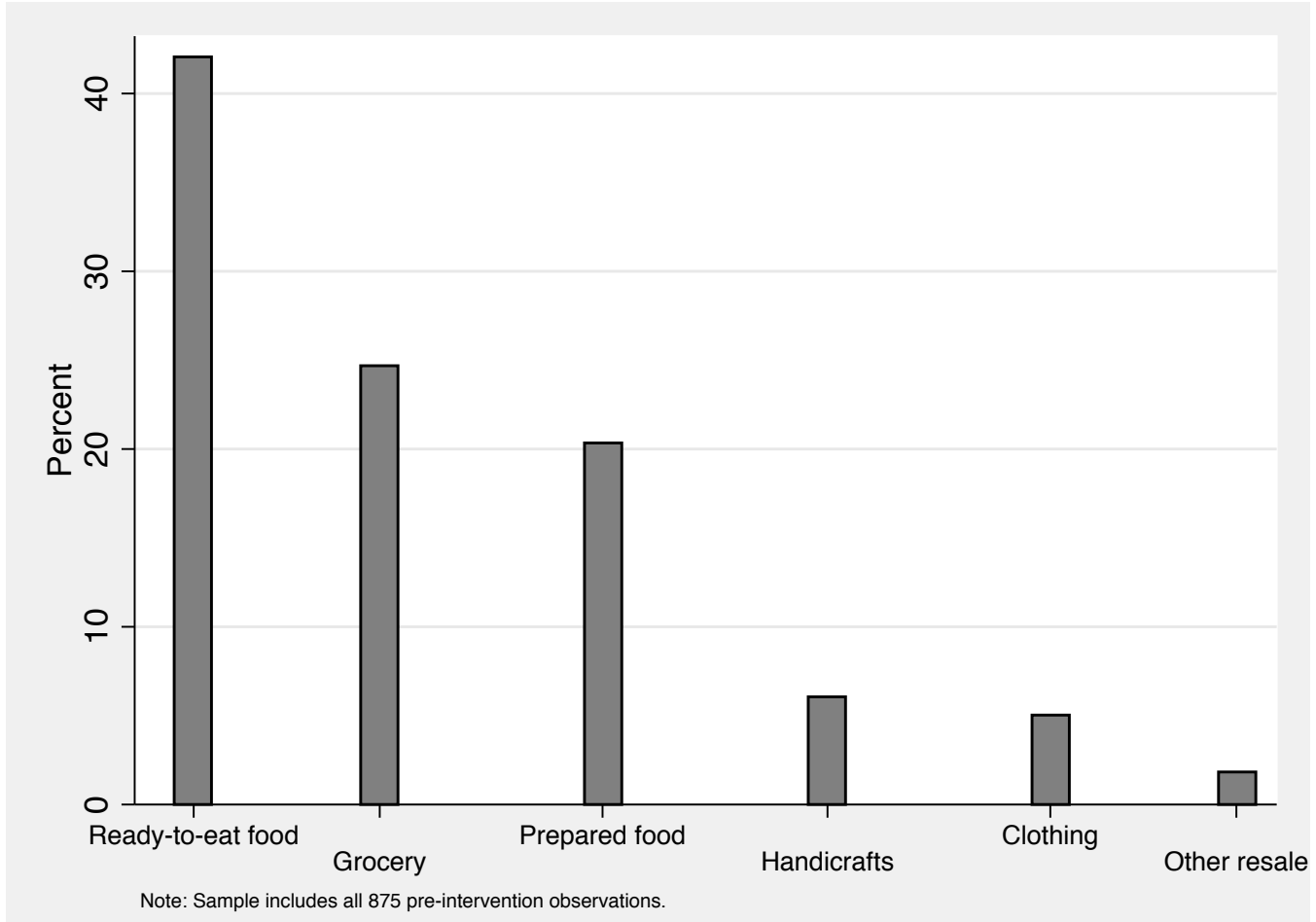

Figure 2: Entrepreneurial choice.

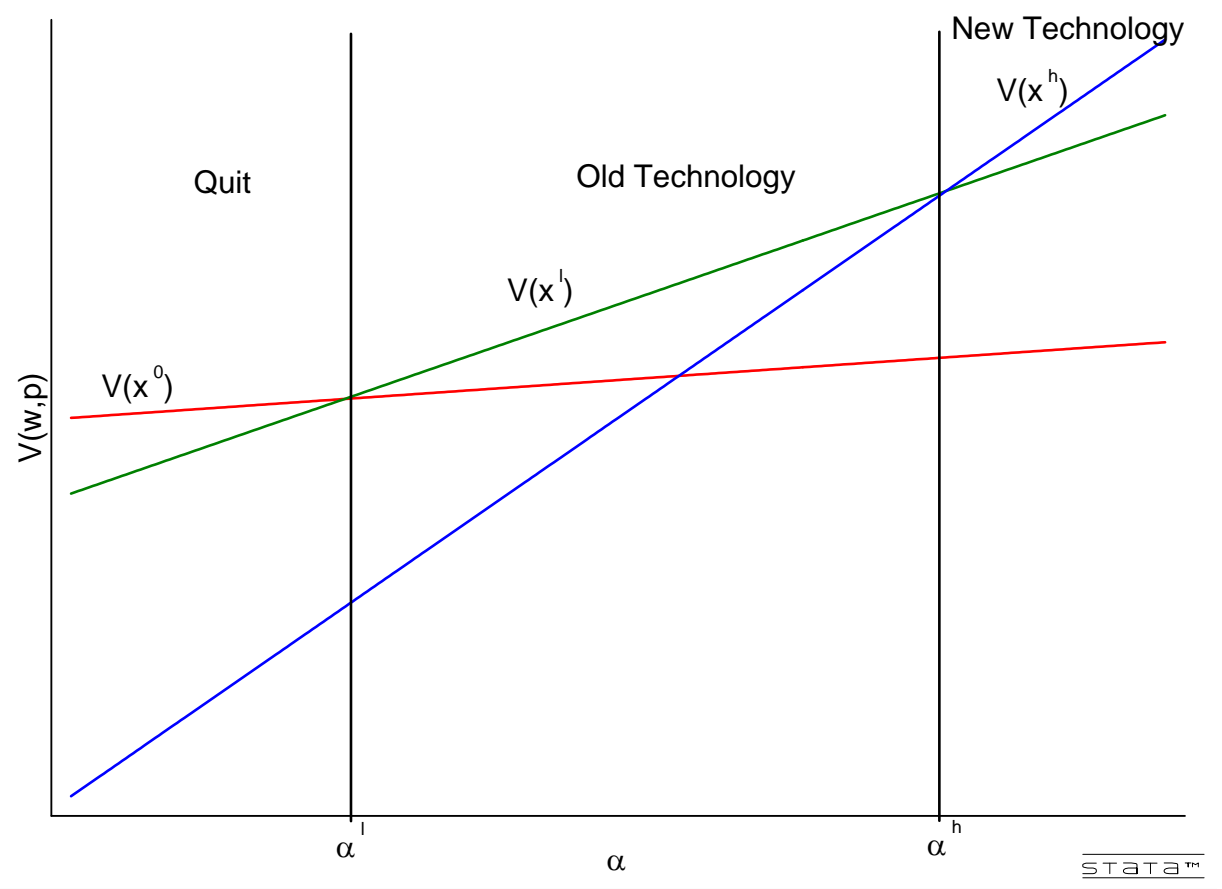


Figure 3: The distribution of baseline (log) daily profits amongst the whole and survived samples of the treatment and control groups

\section{Treatment firms}

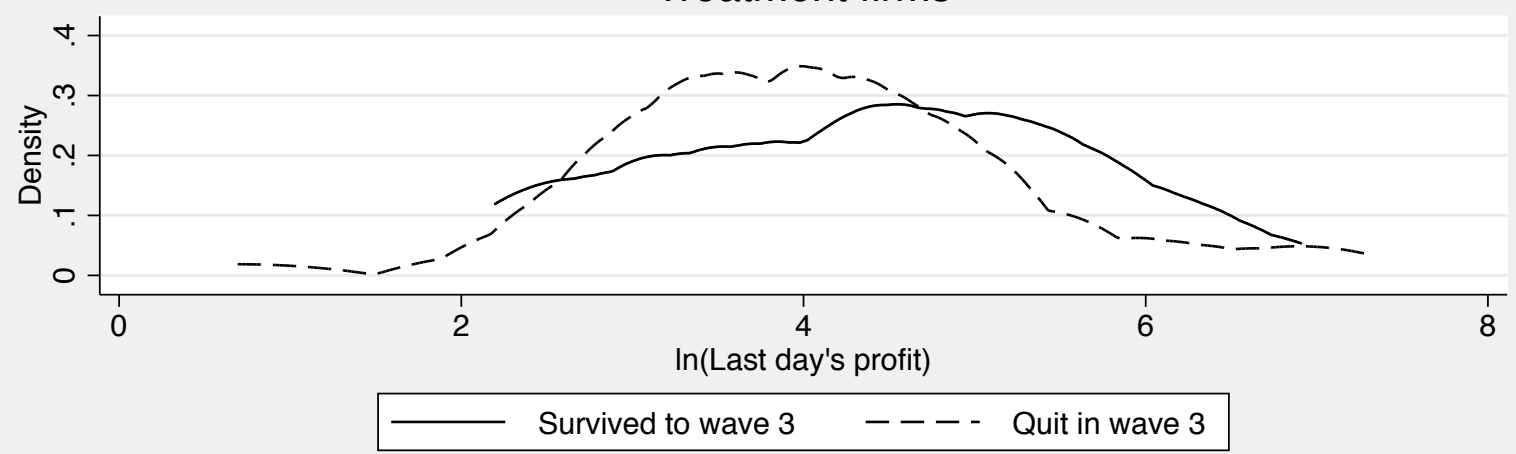

Control firms

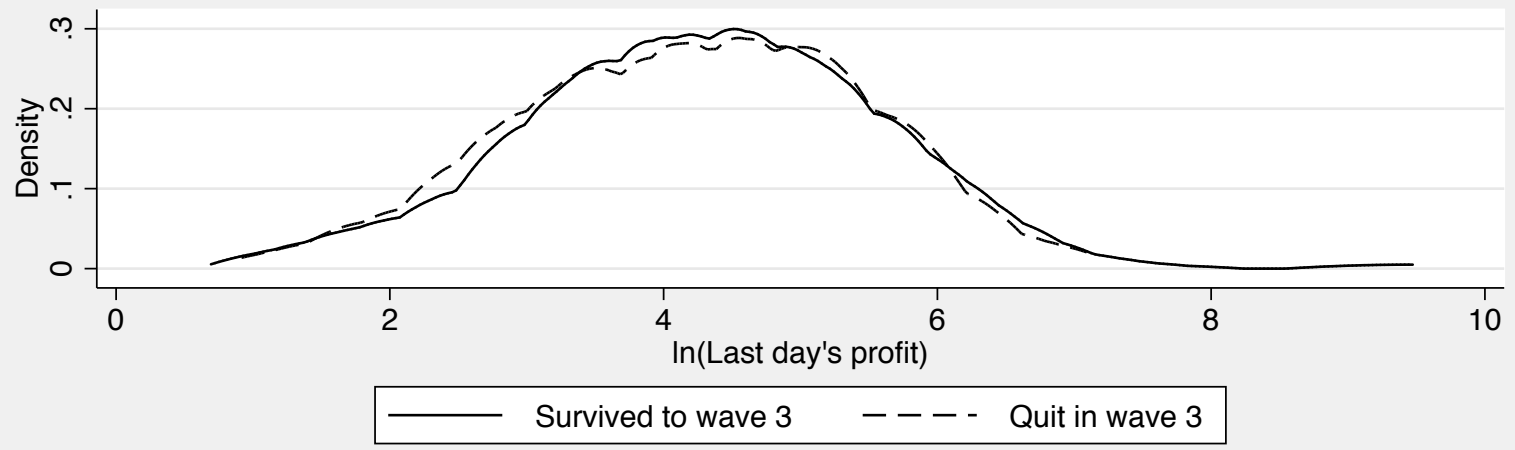


Table 1: Pre-treatment characteristics, by treatment group

\begin{tabular}{|c|c|c|c|c|c|c|}
\hline & \multicolumn{2}{|c|}{ Treatment } & \multicolumn{2}{|c|}{ Control } & \multirow{2}{*}{$\begin{array}{l}(1)=(3) \\
p \text {-value }\end{array}$} & \multirow[b]{2}{*}{$\mathrm{N}$} \\
\hline & Mean & (s.e.) & Mean & (s.e.) & & \\
\hline & $(1)$ & $(2)$ & $(3)$ & $(4)$ & (5) & (6) \\
\hline \multicolumn{7}{|l|}{ Personal Characteristics } \\
\hline Age & 46.04 & $(0.48)$ & 45.67 & $(0.53)$ & 0.64 & 869 \\
\hline Years of education & 5.96 & $(0.32)$ & 6.07 & $(0.13)$ & 0.75 & 846 \\
\hline Roof is made of temporary material & 0.33 & $(0.09)$ & 0.32 & $(0.05)$ & 0.92 & 844 \\
\hline Score on math exercise (percent correct) & 0.39 & $(0.04)$ & 0.47 & $(0.03)$ & 0.11 & 864 \\
\hline Keeps formal business accounts & 0.01 & $(0.01)$ & 0.04 & $(0.01)$ & 0.12 & 873 \\
\hline Weekly hours worked in enterprise & 39.43 & (3.19) & 39.19 & $(1.65)$ & 0.95 & 866 \\
\hline Reservation wage, monthly & $2,986.29$ & $(92.06)$ & $2,974.28$ & $(140.90)$ & 0.94 & 696 \\
\hline Maximum loan available if needed & $8,703.94$ & $(1,079.86)$ & $9,016.38$ & $(1,951.88)$ & 0.92 & 689 \\
\hline Monthly interest rate on a potential loan & 5.48 & $(0.62)$ & 6.43 & $(0.32)$ & 0.20 & 506 \\
\hline \multicolumn{7}{|l|}{ Business Characteristics } \\
\hline Produces goods for sale & 0.62 & $(0.03)$ & 0.67 & $(0.04)$ & 0.28 & 875 \\
\hline Last day's profit & 132.24 & $(16.06)$ & 154.92 & $(22.61)$ & 0.47 & 760 \\
\hline Last day's revenue & 456.16 & $(55.18)$ & 405.96 & $(35.89)$ & 0.54 & 840 \\
\hline Number of clients last day & 14.03 & $(1.47)$ & 14.43 & $(1.16)$ & 0.79 & 808 \\
\hline Total number of workers, including owner & 1.58 & $(0.05)$ & 1.66 & $(0.03)$ & 0.16 & 864 \\
\hline Weekly hours worked by employees & 10.27 & $(2.27)$ & 10.49 & $(0.84)$ & 0.92 & 872 \\
\hline Age of business (years) & 6.77 & $(0.84)$ & 7.62 & $(0.65)$ & 0.42 & 874 \\
\hline Replacement value of business capital & $8,062.61$ & $(1,009.51)$ & $9,238.82$ & $(1,023.20)$ & 0.33 & 875 \\
\hline Registered with the government & 0.15 & $(0.03)$ & 0.21 & $(0.03)$ & 0.04 & 847 \\
\hline \multicolumn{7}{|c|}{$\begin{array}{l}\text { Notes: Sample includes all subjects interviewed in the baseline survey. Asymptotic robust standard errors in } \\
\text { parentheses clustered at the village level; column } 5 \text { reflects wild bootstrapped p-values. All monetary variable are } \\
\text { measured in Mexican Pesos ( } 13 \text { pesos / } 1 \text { U.S. dollar). Reservation wage is the minimum stated monthly wage a } \\
\text { women would accept in order to quit her business. Government registration is with the Secretary of Finance and Public } \\
\text { Credit (SHCP). }\end{array}$} \\
\hline
\end{tabular}


Table 2: The effects of business training on main business outcomes

\begin{tabular}{|c|c|c|c|c|c|}
\hline \multirow[t]{2}{*}{ Outcome $=$} & $\begin{array}{l}\text { Quit her } \\
\text { business }\end{array}$ & $\begin{array}{c}\text { In(Last day's } \\
\text { profit) }\end{array}$ & $\begin{array}{c}\text { In(Last day's } \\
\text { revenue) }\end{array}$ & $\begin{array}{l}\text { In(\# clients } \\
\text { last day) }\end{array}$ & Standardized \\
\hline & $(1)$ & $(2)$ & (3) & $(4)$ & $(5)$ \\
\hline Intention to Treat (ITT) effect & 0.014 & 0.215 & 0.251 & 0.218 & 0.154 \\
\hline p-values, Asymptotic & (0.691) & $(0.060)$ & $(0.038)$ & $(0.082)$ & $(0.051)$ \\
\hline p-value, Wild Bootstrap & $(0.694)$ & $(0.090)$ & $(0.052)$ & $(0.120)$ & (0.049) \\
\hline Pre-program covariates & Yes & Yes & Yes & Yes & Yes \\
\hline Observations & 1,836 & 1,183 & 1,357 & 1,312 & 1,127 \\
\hline
\end{tabular}

Notes: Sample excludes subjects who were not offered treatment in treatment villages. The sample in column 1 includes all firms in the first and second follow-up surveys. The samples in coumns 2-5 include all firms in the baseline survey and surviving firms in the two follow-up surveys. The standardized outcome is constructed as the mean of standardized z-scores of the last day's profits, the last day's revenue, and the number of clients in the last day worked (see text). Covariates include the following pre-program characteristics: number of workers, age of the enterprise, sector, replacement value, lack of business skills, risk aversion, age, education, number of rooms, and score on a business skills exercise. Both methods of calculating $\mathrm{p}$-values allow for intra-village (cluster) correlation.

Table 3: The effects of business training by wave

\begin{tabular}{|c|c|c|c|c|c|}
\hline Outcome $=$ & $\begin{array}{l}\text { Quit her } \\
\text { business }\end{array}$ & $\begin{array}{l}\text { In(Last day's } \\
\text { profit) }\end{array}$ & $\begin{array}{l}\text { In(Last day's } \\
\text { revenue) }\end{array}$ & $\begin{array}{l}\text { In(\# clients } \\
\text { last day) }\end{array}$ & Standardized \\
\hline & (1) & $(2)$ & (3) & $(4)$ & (5) \\
\hline ITT wave 2 & 0.013 & 0.220 & 0.240 & 0.231 & 0.154 \\
\hline p-values, Asymptotic & $(0.807)$ & $(0.054)$ & $(0.027)$ & $(0.043)$ & $(0.038)$ \\
\hline p-value, Wild Bootstrap & $(0.810)$ & $(0.117)$ & (0.109) & $(0.131)$ & $(0.074)$ \\
\hline ITT wave 3 & 0.019 & 0.216 & 0.279 & 0.193 & 0.157 \\
\hline p-values, Asymptotic & $(0.739)$ & $(0.325)$ & $(0.162)$ & $(0.339)$ & $(0.249)$ \\
\hline$p$-value, Wild Bootstrap & $(0.760)$ & $(0.200)$ & $(0.217)$ & $(0.206)$ & $(0.152)$ \\
\hline $\begin{array}{l}\text { H0: ITT wave } 2 \text { = ITT wave } 3 \text {, } \\
\text { p-value, Wild bootstrap }\end{array}$ & 0.996 & 0.986 & 0.871 & 0.876 & 0.975 \\
\hline Observations & 1,836 & 1,183 & 1,357 & 1,312 & 1,127 \\
\hline
\end{tabular}

Notes: Sample excludes subjects who were not offered treatment in treatment villages. The sample in column 1 includes all firms in the first and second follow-up surveys. The samples in coumns 2-5 include all firms in the baseline survey and surviving firms in the two follow-up surveys. The standardized outcome is constructed as the mean of standardized z-scores of the last day's profits, the last day's revenue, and the number of clients in the last day worked (see text). Covariates included (see text). Both methods of calculating $p$-values allow for intra-village (cluster) correlation. 
Table 4: Robustness of the main effects

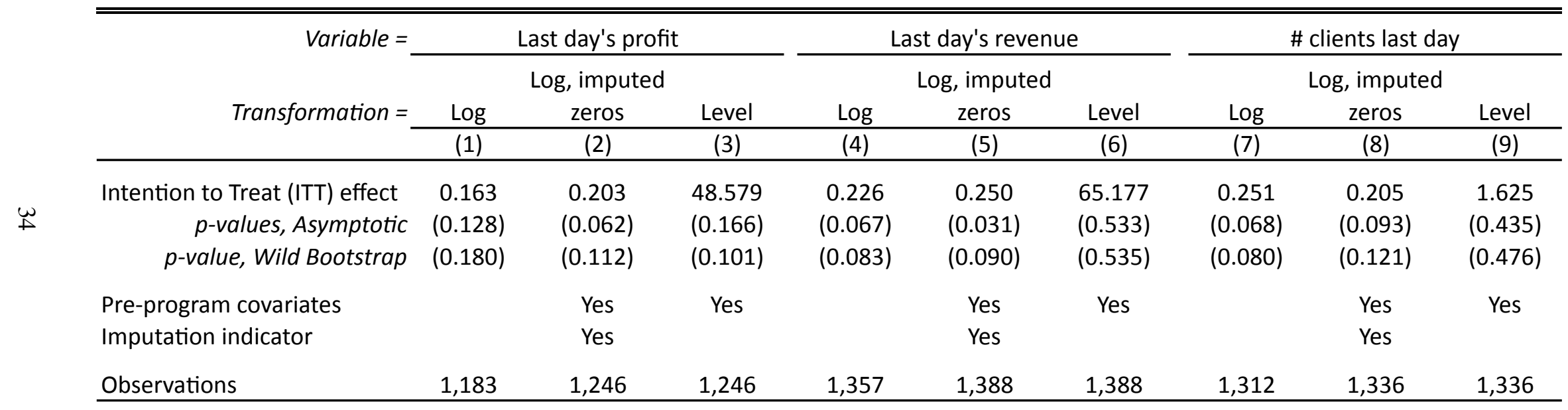

Notes: Sample excludes subjects who were not offered treatment in treatment villages. The standardized outcome is constructed as the mean of standardized z-scores (see text). Covariates included (see text). Both methods of calculating p-values allow for intra-village (cluster) correlation. 
Table 5: Possible mechanisms

\begin{tabular}{cccccc}
\hline \hline & \multicolumn{5}{c}{ Outcomes calculated from good-specific data } \\
\cline { 2 - 6 } Outcome & $\begin{array}{c}\text { In(Last day's } \\
\text { profit) }\end{array}$ & $\begin{array}{c}\text { In(Last day's } \\
\text { revenue) }\end{array}$ & $\begin{array}{c}\text { In(\# goods } \\
\text { for sale) }\end{array}$ & $\begin{array}{c}\text { In(Mean } \\
\text { unit cost) }\end{array}$ & $\begin{array}{c}\text { In(Mean } \\
\text { unit price) }\end{array}$ \\
\cline { 2 - 7 } & $(1)$ & $(2)$ & $(3)$ & $(4)$ & $(5)$ \\
\hline $\begin{array}{c}\text { Intention to Treat (ITT) effect } \\
p \text {-value, Asymptotic }\end{array}$ & 0.166 & 0.237 & 0.116 & -0.293 & 0.004 \\
$p$-value, Wild Bootstrap & $(0.460)$ & $(0.142)$ & $(0.138)$ & $(0.037)$ & $(0.938)$ \\
Observations & 834 & $(0.170)$ & $(0.155)$ & $(0.074)$ & $(0.922)$ \\
\hline
\end{tabular}

Notes: Sample excludes subjects who were not offered treatment in treatment villages. Covariates included (see text). Both methods of calculating p-values allow for intra-village (cluster) correlation.

Table 6: Effects on goods that were dropped across waves, kept across waves, and added postintervention

\begin{tabular}{llcccc}
\hline \hline & Goods that & $\begin{array}{c}\text { Intention to Treat } \\
\text { (ITT) effect }\end{array}$ & $\begin{array}{c}\text { p-value, } \\
\text { Asymptotic }\end{array}$ & $\begin{array}{c}\text { p-value, Wild } \\
\text { Bootstrap }\end{array}$ & Observations \\
\cline { 2 - 6 } Outcome: & were: & $(1)$ & $(2)$ & $(3)$ & $(4)$ \\
\hline In(Last day's profit) & Dropped & -0.476 & $(0.271)$ & $(0.158)$ & 120 \\
& Kept & 0.202 & $(0.567)$ & $(0.684)$ & 467 \\
& Added & -0.035 & $(0.853)$ & $(0.872)$ & 97 \\
$\ln$ (Last day's revenue) & Dropped & -0.364 & $(0.357)$ & $(0.861)$ & 129 \\
& Kept & 0.171 & $(0.600)$ & $(0.734)$ & 650 \\
& Added & 0.245 & $(0.211)$ & $(0.220)$ & 282 \\
$\ln$ (Mean unit cost) & Dropped & -0.039 & $(0.802)$ & $(0.917)$ & 147 \\
& Kept & -0.300 & $(0.090)$ & $(0.045)$ & 533 \\
& Added & -0.072 & $(0.732)$ & $(0.955)$ & 109 \\
$\ln$ (Mean unit price) & Dropped & -0.207 & $(0.277)$ & $(0.464)$ & 160 \\
& Kept & 0.009 & $(0.878)$ & $(0.992)$ & 732 \\
& Added & -0.027 & $(0.827)$ & $(0.980)$ & 319 \\
\hline
\end{tabular}

Notes: All sample excludes subjects who were not offered treatment in treatment villages. Dropped goods specifications use data from the pre-treatment wave only. Kept goods specifications use data from the pretreatment wave and first post-treatment wave. Added goods specifications use data from the first post-treatment wave only. Covariates included (see text). Both methods of calculating $p$-values allow for intra-village (cluster) correlation. 
Table 7: Possible mechanisms

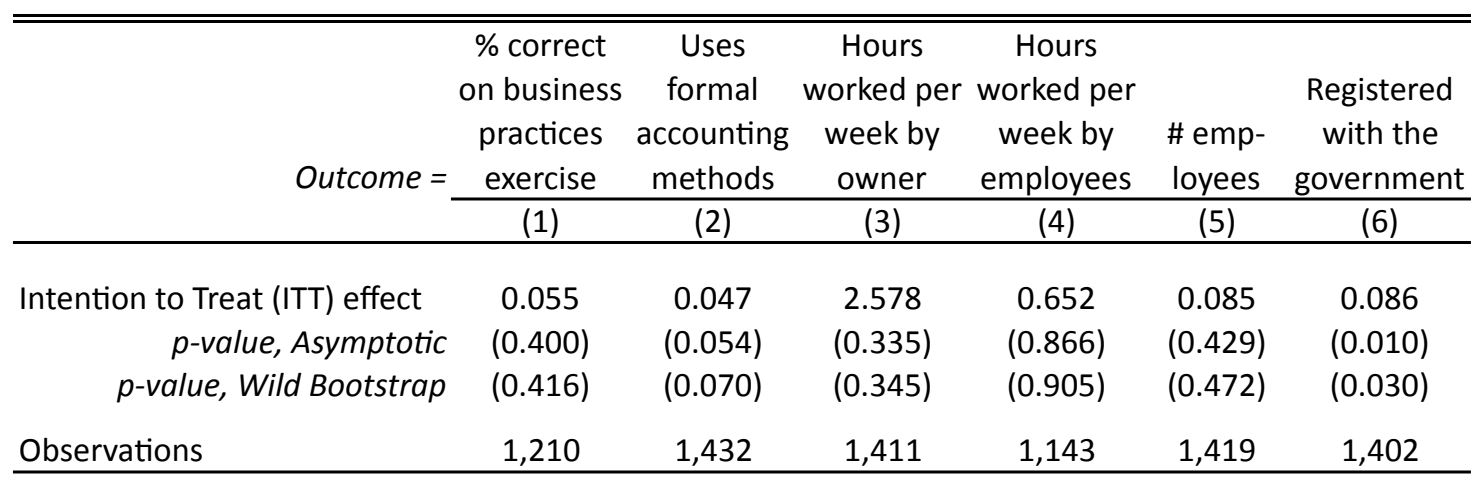

Notes: Sample excludes subjects who were not offered treatment in treatment villages. Covariates included (see text). Both methods of calculating p-values allow for intra-village (cluster) correlation. 
Table 8: The indirect effects of business training

\begin{tabular}{|c|c|c|c|c|}
\hline Outcome: & $\begin{array}{l}\text { Indirect Treatment } \\
\text { Effect (ITE) }\end{array}$ & $\begin{array}{c}\begin{array}{c}\text { p-value, } \\
\text { Asymptotic }\end{array} \\
(2)\end{array}$ & $\begin{array}{c}\begin{array}{c}\text { p-value, } \\
\text { Wild Bootstrap }\end{array} \\
\text { (3) }\end{array}$ & $\frac{\text { Obs. }}{\text { (4) }}$ \\
\hline Quit her business & -0.029 & $(0.508)$ & (0.514) & 1,907 \\
\hline \multicolumn{5}{|l|}{ Main business outcomes } \\
\hline In(Last day's profit) & -0.110 & $(0.363)$ & $(0.340)$ & 1,250 \\
\hline In(Last day's revenue) & 0.056 & $(0.548)$ & (0.555) & 1,430 \\
\hline In(\# clients last day) & 0.073 & $(0.593)$ & (0.595) & 1,371 \\
\hline Standardized & 0.013 & $(0.846)$ & $(0.866)$ & 1,189 \\
\hline \multicolumn{5}{|l|}{ Outcomes calculated from good-specific data } \\
\hline In(Last day's profit) & -0.120 & $(0.423)$ & (0.164) & 874 \\
\hline In(Last day's revenue) & 0.128 & $(0.137)$ & (0.137) & 1,113 \\
\hline In(\# goods for sale) & 0.015 & $(0.802)$ & (0.796) & 1,495 \\
\hline $\ln ($ Mean unit cost) & 0.221 & $(0.127)$ & (0.139) & 1,031 \\
\hline In(Mean unit price) & 0.072 & $(0.294)$ & $(0.326)$ & 1,474 \\
\hline \multicolumn{5}{|l|}{ Other business outcomes } \\
\hline Percent correct on business practices exercise & 0.001 & (0.987) & $(0.942)$ & 1,239 \\
\hline Uses formal accounting methods & 0.057 & $(0.008)$ & $(0.033)$ & 1,501 \\
\hline Hours worked per week by owner & 3.956 & $(0.050)$ & $(0.078)$ & 1,479 \\
\hline Hours worked per week by employees & 2.289 & $(0.461)$ & $(0.131)$ & 1,194 \\
\hline Number of employees & 0.016 & $(0.804)$ & $(0.786)$ & 1,485 \\
\hline Registered with the government & -0.037 & $(0.313)$ & $(0.337)$ & 1,473 \\
\hline
\end{tabular}

Notes: Sample excludes subjects who were offered treatment in treatment villages. The standardized outcome is constructed as the mean of standardized z-scores of the last day's profits, the last day's revenue, and the number of clients in the last day worked (see text). Covariates included (see text). Both methods of calculating $p$-values allow for intra-village (cluster) correlation. 
Table 9: Effects of training amongst those above and below the median of pre-intervention profits

\begin{tabular}{|c|c|c|c|c|c|c|c|c|c|c|}
\hline \multirow{3}{*}{$\begin{array}{r}\text { Outcome }= \\
\text { Sample }=\text {... median } \\
\text { baseline profits }\end{array}$} & \multicolumn{2}{|c|}{$\begin{array}{l}\text { Quit her } \\
\text { business }\end{array}$} & \multicolumn{2}{|c|}{$\begin{array}{l}\ln \text { (Last day's } \\
\text { profit) }\end{array}$} & \multicolumn{2}{|c|}{$\begin{array}{l}\text { In(Last day's } \\
\text { revenue) }\end{array}$} & \multicolumn{2}{|c|}{$\begin{array}{c}\text { In(\# clients last } \\
\text { day) }\end{array}$} & \multicolumn{2}{|c|}{ Standardized } \\
\hline & Below & Above & Below & Above & Below & Above & Below & Above & Below & Above \\
\hline & $(1)$ & $(2)$ & (3) & (4) & (5) & $(6)$ & $(7)$ & (8) & (9) & $(10)$ \\
\hline \multicolumn{11}{|l|}{ Intention to Treat (ITT) } \\
\hline p-values, Asymptotic & $(0.754)$ & $(0.271)$ & (0.739) & $(0.074)$ & $(0.872)$ & $(0.068)$ & (0.675) & (0.009) & (0.969) & $(0.006)$ \\
\hline p-value, Wild Bootstrap & $(0.748)$ & $(0.298)$ & $(0.776)$ & $(0.058)$ & $(0.848)$ & $(0.070)$ & $(0.672)$ & $(0.020)$ & $(0.888)$ & $(0.006)$ \\
\hline $\begin{array}{l}\text { Below = Above, } p \text {-value, } \\
\text { Wild Bootstrap }\end{array}$ & \multicolumn{2}{|c|}{0.921} & \multicolumn{2}{|c|}{0.605} & \multicolumn{2}{|c|}{0.840} & \multicolumn{2}{|c|}{0.671} & \multicolumn{2}{|c|}{0.799} \\
\hline Observations & 825 & 753 & 547 & 551 & 551 & 607 & 597 & 562 & 527 & 521 \\
\hline
\end{tabular}

Notes: Sample excludes subjects who were not offered treatment in treatment villages. The standardized outcome is constructed as the mean of standardized z-scores of the last day's profits, the last day's revenue, and the number of clients in the last day worked (see text). Covariates included (see text). Both methods of calculating $\mathrm{p}$-values allow for intra-village (cluster) correlation. 
Table 10: Quitting and attrition by treatment and baseline profits

\begin{tabular}{|c|c|c|c|c|c|c|}
\hline \multirow{3}{*}{$\begin{array}{r}\text { Outcome }= \\
\text { Lowest ... of last day's profits }=\end{array}$} & \multicolumn{3}{|c|}{ Quit the enterprise } & \multicolumn{3}{|c|}{ Did not quit or attrite } \\
\hline & $1 \%$ & $3 \%$ & $5 \%$ & $1 \%$ & $3 \%$ & $5 \%$ \\
\hline & (1) & $(2)$ & (3) & (4) & (5) & (6) \\
\hline Treated & 0.004 & 0.006 & 0.011 & -0.013 & -0.014 & -0.018 \\
\hline$p$-values, Asymptotic & $(0.950)$ & (0.933) & (0.879) & $(0.808)$ & $(0.793)$ & $(0.744)$ \\
\hline$p$-value, Wild Bootstrap & $(0.922)$ & $(0.960)$ & (0.912) & $(0.988)$ & (0.985) & (0.982) \\
\hline Lowest ... of last day's profits pre- & & & & & & \\
\hline treatment & -0.033 & 0.008 & -0.006 & 0.031 & -0.000 & 0.016 \\
\hline$p$-values, Asymptotic & $(0.768)$ & (0.945) & (0.966) & $(0.718)$ & $(0.996)$ & $(0.883)$ \\
\hline$p$-value, Wild Bootstrap & $(0.750)$ & (0.952) & (0.926) & $(0.965)$ & $(1.000)$ & $(0.985)$ \\
\hline Treated $\mathrm{x}$ Lowest ... of last day's & & & & & & \\
\hline profits pre-treatment & 0.393 & 0.354 & -0.143 & -0.399 & -0.369 & -0.013 \\
\hline$p$-values, Asymptotic & (0.005) & (0.009) & $(0.703)$ & $(0.008)$ & $(0.015)$ & (0.968) \\
\hline$p$-value, Wild Bootstrap & $(0.002)$ & $(0.002)$ & $(0.732)$ & $(0.000)$ & $(0.000)$ & (0.988) \\
\hline Observations & 463 & 463 & 463 & 553 & 553 & 553 \\
\hline
\end{tabular}

Notes: ${ }^{* * *} p<0.01,{ }^{* *} p<0.05,{ }^{*} p<0.1$

All columns include only a single survey wave, and excludes subjects who were not offered treatment in treatment villages. An entrepreneur is defined as quitting the enterprise if she is not running her business in the second followup survey, and she is defined as not quitting or attriting if she did not quit or attrite in the second followup survey. Covariates included (see text). Both methods of calculating $p$-values allow for intra-village (cluster) correlation. 
Table 11: Effects of training amongst those above and below the median of pre-intervention profits

\begin{tabular}{|c|c|c|c|c|c|c|c|c|c|c|}
\hline \multirow{4}{*}{$\begin{array}{r}\text { Outcome }= \\
\text { Sample }=\text {... median } \\
\text { baseline profits }\end{array}$} & \multicolumn{10}{|c|}{ Outcomes calculated from good-specific data } \\
\hline & \multicolumn{2}{|c|}{$\begin{array}{c}\text { In(Last day's } \\
\text { profit) }\end{array}$} & \multicolumn{2}{|c|}{$\begin{array}{c}\text { In(Last day's } \\
\text { revenue) } \\
\end{array}$} & \multicolumn{2}{|c|}{$\begin{array}{c}\text { In(\# goods for } \\
\text { sale) } \\
\end{array}$} & \multicolumn{2}{|c|}{$\begin{array}{c}\text { In(Mean unit } \\
\text { cost) }\end{array}$} & \multicolumn{2}{|c|}{$\begin{array}{c}\text { In(Mean unit } \\
\text { price) }\end{array}$} \\
\hline & Below & Above & Below & Above & Below & Above & Below & Above & Below & Above \\
\hline & $(1)$ & $(2)$ & (3) & $(4)$ & $(5)$ & $(6)$ & (7) & $(8)$ & (9) & $(10)$ \\
\hline \multicolumn{11}{|l|}{ Intention to Treat (ITT) } \\
\hline effect & -0.112 & 0.343 & -0.047 & 0.179 & 0.019 & 0.152 & -0.235 & -0.202 & -0.119 & 0.075 \\
\hline$p$-values, Asymptotic & (0.749) & $(0.161)$ & $(0.857)$ & $(0.330)$ & $(0.860)$ & $(0.088)$ & (0.313) & $(0.361)$ & (0.219) & (0.589) \\
\hline$p$-value, Wild Bootstrap & $(0.261)$ & $(0.275)$ & $(0.207)$ & $(0.235)$ & $(0.894)$ & $(0.098)$ & (0.326) & $(0.450)$ & $(0.226)$ & (0.618) \\
\hline $\begin{array}{l}\text { Below = Above, } p \text {-value, } \\
\text { Wild Bootstrap }\end{array}$ & & 338 & 0.5 & 67 & & 914 & & 892 & & 503 \\
\hline Observations & 369 & 363 & 481 & 444 & 635 & 593 & 430 & 420 & 626 & 579 \\
\hline
\end{tabular}

Notes: Sample excludes subjects who were not offered treatment in treatment villages. The standardized outcome is constructed as the mean of standardized z-scores (see text). Covariates included (see text). Both methods of calculating $p$ values allow for intra-village (cluster) correlation. 
Table 12: Effects of training amongst those above and below the median of pre-intervention profits

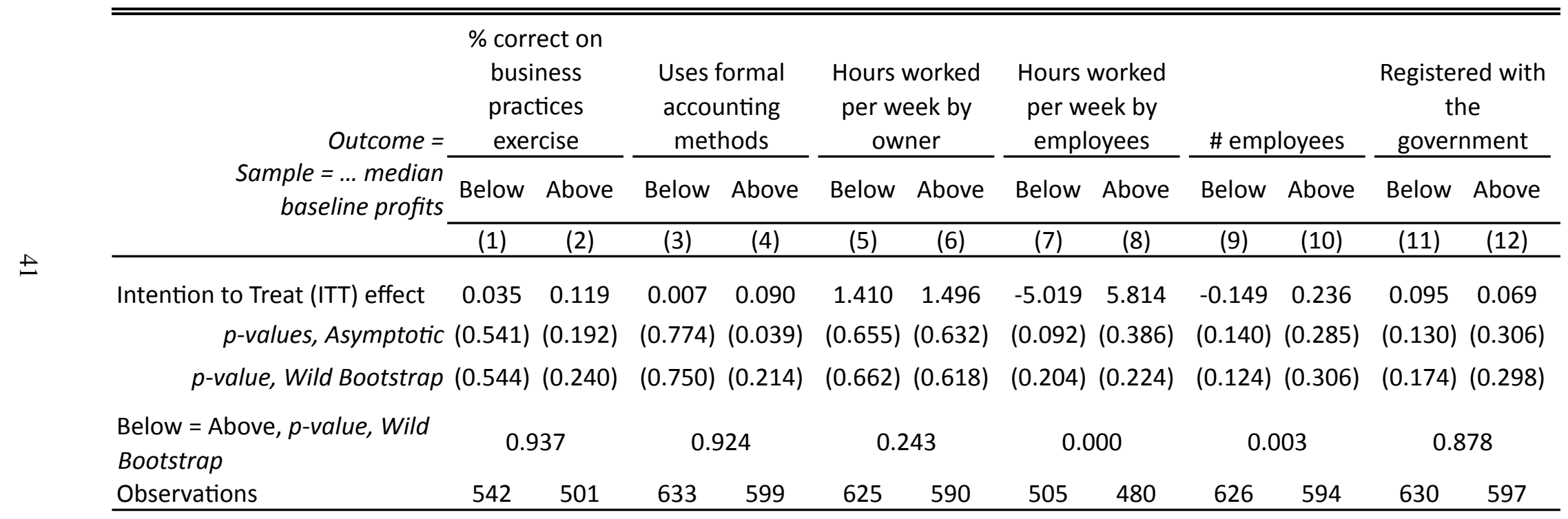

Notes: Sample excludes subjects who were not offered treatment in treatment villages. The standardized outcome is constructed as the mean of standardized z-scores (see text). Covariates included (see text). Both methods of calculating p-values allow for intra-village (cluster) correlation. 


\section{FOR ONLINE PUBLICATION ONLY}

\section{APPENDIX}

\section{A. Bounds on Intention to Treat Effects}

As discussed in Section 4.4 of the text, our sample of entrepreneurs shrinks overtime due to sample attrition. While the mean attrition rates do not differ significantly between the treatment and control groups, we nonetheless present in this appendix the results of bounding exercises that accounts for possible non-random attrition across groups.

We estimate bounds using a modified version of Lee's methodology (Lee, 2009) that allows us to maintain our difference-in-differences estimation strategy. Specifically, lower and upper bounds are calculated by first using Lee's methodology to trim each post-intervention period independently, and then estimating our difference-in-difference model with this trimmed data and the full preintervention sample. Table 4 contains both upper and lower bounds on the ITTs calculated in this manner, for all of the main business-related outcomes. Perhaps not surprisingly, given the small and insignificant differential attrition across treatment groups, estimated bounds are tightly centered around estimated treatment effects. 
Appendix Figure 1: An in-class example (Panel A) and an in-class exercise (Panel B) used in CREAs business literacy course.

\section{Panel A}

Supose that Belen has a store that sells beauty products. She sells makeup, hair products, and products for nails. Below is a list of articles that she sold today:

\begin{tabular}{|l|l|r|r|}
\hline \multicolumn{4}{|c|}{ Belen's Beauty Products } \\
\hline No. & Article & Unit Price & \multicolumn{1}{l|}{ Subtotal } \\
\hline 3 & Nail files & $\$ 10$ & $\$ 30$ \\
\hline 1 & Anti-dandruf shampoo & $\$ 30$ & $\$ 30$ \\
\hline 2 & Eye shadow & $\$ 20$ & $\$ 40$ \\
\hline & & & \\
\hline & & TOTAL & $\$ 100$ \\
\hline
\end{tabular}

As we can see in this bill of sale, Belen sold 3 nail files for 10 pesos each $(3 \times \$ 10)$, generating a revenue of 30 pesos, 1 anti-dandruff shampoo for 30 pesos $(1 \times \$ 30)$ gererating a revenue of 30 pesos, and 2 eye shadows for 20 pesos each $(2 \times \$ 20)$ generating a revenue of 40 pesos. In total, Belen had revenue of 100 pesos today.

\section{Panel B}

Leticia has a business selling pineapple candy that she produces herself along with a small store in which she sells her candies and many other food items, from fruit and vegetables to cookies, flour, soda, etc. Leticia needs you to help her calculate her revenue from September 17 th. Below is a list of products that she sold. Please calculate the revenue for each item and then calculate her total revenue.

\begin{tabular}{|l|l|l|l|}
\hline \multicolumn{4}{|c|}{ Lety's Corner Store } \\
Sales on September 17 & th \\
\hline No. & Article & Unit Price & Subtotal \\
\hline 20 & Pineapple candy & $\$ 3.50$ & \\
\hline 5 & Kilos of tomatoes & $\$ 6$ & \\
\hline 10 & Kilos of onion & $\$ 5$ & \\
\hline 4 & Kilos of orange & $\$ 10$ & \\
\hline 6 & Gansitos Marinela $\AA$ & $\$ 4$ & \\
\hline 8 & Bottles of Coca-Cola $₫$ & $\$ 5$ & \\
& & & \\
\hline
\end{tabular}


Appendix Figure 2: The applied math question given to entrepreneurs in the baseline and followup surveys

Section 10 Exercise

Now we are going to do an exercise, but I want to let you know that the numbers are invented, as is the example. If you have any questions, please ask me.

If they do no answer of don't want to answer, STOP, and leave

the other parts blank.

Part 1: Imagine that you produce 5 tablecloths every week and that each tablecloth costs 10 pesos.

Suppose the first week you sell

1 tablecloth

The second week you sell

2 tablecloths

The third week you sell

2 tablecloths

and the fourth week you sell

5 tablecloths

a) How many tablecloths do you have left over at the end of the month?

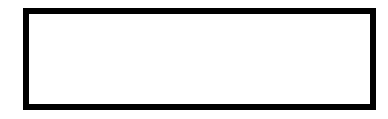

b) What is your income for this month?

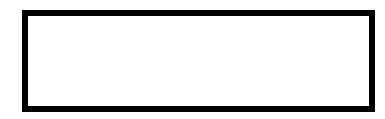

Part 2: Each week, you spend 5 pesos for cloth and 5 pesos in salaries in order to make tablecloths. Each month has 4 weeks.

c) How much are your profits at the end of the month?

That is, how much money do you earn this month?

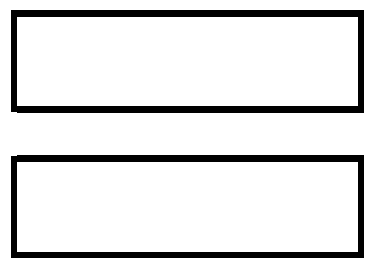

d) If your profits were to be zero for this month, what price should you have set for your tablecloths? 
Appendix Table 1: Pre-treatment characteristics of treatment group entrepreneurs, by attendance status

\begin{tabular}{|c|c|c|c|c|c|c|}
\hline & \multicolumn{2}{|c|}{ Attended } & \multicolumn{2}{|c|}{ Did not attend } & \multirow{2}{*}{$\begin{array}{l}(1)=(3) \\
p \text {-value }\end{array}$} & \multirow[b]{2}{*}{$\mathrm{N}$} \\
\hline & Mean & (s.e.) & Mean & (s.e.) & & \\
\hline & $(1)$ & $(2)$ & $(3)$ & $(4)$ & $(5)$ & (6) \\
\hline \multicolumn{7}{|l|}{ Personal Characteristics } \\
\hline Age & 46.98 & $(0.91)$ & 44.25 & (1.80) & 0.35 & 163 \\
\hline Years of education & 6.07 & $(0.41)$ & 5.76 & $(0.44)$ & 0.58 & 161 \\
\hline Roof is made of temporary material & 0.38 & (0.11) & 0.22 & $(0.07)$ & 0.09 & 160 \\
\hline Score on math exercise (percent correct) & 0.39 & $(0.05)$ & 0.38 & $(0.06)$ & 0.76 & 164 \\
\hline Keeps formal business accounts & 0.01 & $(0.01)$ & 0.02 & $(0.02)$ & 0.68 & 164 \\
\hline Weekly hours worked in enterprise & 37.84 & (4.02) & 42.43 & (4.03) & 0.34 & 162 \\
\hline Reservation wage, monthly & $3,064.04$ & $(140.02)$ & $2,808.85$ & (271.85) & 0.48 & 128 \\
\hline Maximum loan available if needed & $8,479.91$ & $(1,595.83)$ & $9,190.24$ & $(1,792.58)$ & 0.87 & 130 \\
\hline Monthly interest rate on a potential loan & 5.94 & (0.64) & 4.38 & $(1.07)$ & 0.21 & 101 \\
\hline \multicolumn{7}{|l|}{ Business Characteristics } \\
\hline Produces goods for sale & 0.67 & $(0.02)$ & 0.53 & $(0.08)$ & 0.14 & 164 \\
\hline Last day's profit & 110.83 & $(28.90)$ & 177.91 & $(43.62)$ & 0.36 & 141 \\
\hline Last day's revenue & 337.85 & (75.24) & 690.53 & $(243.80)$ & 0.29 & 158 \\
\hline Number of clients last day & 13.76 & (1.86) & 14.55 & (3.65) & 0.82 & 152 \\
\hline Total number of workers, including owner & 1.64 & $(0.06)$ & 1.48 & $(0.13)$ & 0.32 & 159 \\
\hline Weekly hours worked by employees & 11.85 & (2.86) & 7.32 & (3.21) & 0.29 & 164 \\
\hline Age of business (years) & 6.68 & $(0.66)$ & 6.94 & (1.63) & 0.85 & 164 \\
\hline Replacement value of business capital & $7,441.43$ & $(1,310.72)$ & $9,228.68$ & $(1,819.19)$ & 0.42 & 164 \\
\hline Registered with the government & 0.16 & $(0.04)$ & 0.11 & $(0.03)$ & 0.27 & 160 \\
\hline
\end{tabular}

Notes: Sample includes all women assigned to treatment who did not attrite post-intervention. Asymptotic robust standard errors in parentheses clustered at the village level; column 5 reflects wild bootstrapped p-values. All monetary variable are measured in Mexican Pesos ( 13 pesos / 1 U.S. dollar). Reservation wage is the minimum stated monthly wage a women would accept in order to quit her business. Government registration is with the Secretary of Finance and Public Credit (SHCP). 
Appendix Table 2: Pre-treatment characteristics of entrepreneurs, by attrition status

\begin{tabular}{|c|c|c|c|c|c|c|}
\hline & \multicolumn{2}{|c|}{ Ever attrited } & \multicolumn{2}{|c|}{ Never attrited } & \multirow{2}{*}{$\begin{array}{l}(1)=(3) \\
p \text {-value }\end{array}$} & \multirow[b]{2}{*}{$\mathrm{N}$} \\
\hline & Mean & (s.e.) & Mean & (s.e.) & & \\
\hline & $(1)$ & $(2)$ & $(3)$ & $(4)$ & $(5)$ & (6) \\
\hline \multicolumn{7}{|l|}{ Personal Characteristics } \\
\hline Age & 44.89 & $(1.04)$ & 46.04 & $(0.44)$ & 0.28 & 869 \\
\hline Years of education & 6.33 & $(0.21)$ & 5.95 & $(0.14)$ & 0.09 & 846 \\
\hline Roof is made of temporary material & 0.28 & $(0.05)$ & 0.33 & (0.06) & 0.23 & 844 \\
\hline Score on math exercise (percent correct) & 0.43 & $(0.03)$ & 0.46 & $(0.03)$ & 0.34 & 864 \\
\hline Keeps formal business accounts & 0.03 & $(0.01)$ & 0.03 & $(0.01)$ & 0.93 & 873 \\
\hline Weekly hours worked in enterprise & 42.34 & $(2.42)$ & 38.14 & (1.47) & 0.11 & 866 \\
\hline Reservation wage, monthly & $3,076.29$ & $(215.29)$ & $2,942.19$ & $(146.24)$ & 0.66 & 696 \\
\hline Maximum loan available if needed & $7,316.22$ & $(1,004.10)$ & $9,559.86$ & $(2,112.11)$ & 0.33 & 689 \\
\hline Monthly interest rate on a potential loan & 6.66 & $(0.31)$ & 6.10 & $(0.37)$ & 0.23 & 506 \\
\hline \multicolumn{7}{|l|}{ Business Characteristics } \\
\hline Produces goods for sale & 0.62 & $(0.04)$ & 0.68 & $(0.03)$ & 0.03 & 875 \\
\hline Last day's profit & 123.16 & $(11.78)$ & 160.35 & $(23.28)$ & 0.11 & 760 \\
\hline Last day's revenue & 347.61 & $(20.98)$ & 439.45 & $(38.20)$ & 0.04 & 840 \\
\hline Number of clients last day & 14.18 & $(1.21)$ & 14.42 & $(1.05)$ & 0.80 & 808 \\
\hline Total number of workers, including owner & 1.56 & $(0.05)$ & 1.68 & $(0.04)$ & 0.08 & 864 \\
\hline Weekly hours worked by employees & 10.35 & $(1.24)$ & 10.48 & $(1.13)$ & 0.93 & 872 \\
\hline Age of business (years) & 6.55 & $(0.70)$ & 7.79 & $(0.70)$ & 0.17 & 874 \\
\hline Replacement value of business capital & $7,298.10$ & $(1,066.35)$ & $9,628.18$ & $(1,163.03)$ & 0.18 & 875 \\
\hline Registered with the government & 0.20 & $(0.04)$ & 0.20 & $(0.03)$ & 0.52 & 847 \\
\hline
\end{tabular}

Notes: Sample includes all subjects interviewed in the baseline survey. A subject "ever attrited" if they were not surveyed in either the first or second post-treatment survey. Asymptotic robust standard errors in parentheses clustered at the village level; column 5 reflects wild bootstrapped p-values. All monetary variable are measured in Mexican Pesos ( 13 pesos / 1 U.S. dollar). Reservation wage is the minimum stated monthly wage a women would accept in order to quit her business. Government registration is with the Secretary of Finance and Public Credit (SHCP). 
Appendix Table 3: Pre-treatment characteristics of entrepreneurs, by quitting status

\begin{tabular}{|c|c|c|c|c|c|c|}
\hline & \multicolumn{2}{|c|}{ Ever quit } & \multicolumn{2}{|c|}{ Did not quit } & \multirow{2}{*}{$\begin{array}{l}(1)=(3) \\
p \text {-value }\end{array}$} & \multirow[b]{2}{*}{$\mathrm{N}$} \\
\hline & Mean & (s.e.) & Mean & (s.e.) & & \\
\hline & $(1)$ & $(2)$ & $(3)$ & $(4)$ & $(5)$ & (6) \\
\hline \multicolumn{7}{|l|}{ Personal Characteristics } \\
\hline Age & 44.31 & $(0.58)$ & 47.39 & $(0.68)$ & 0.00 & 822 \\
\hline Years of education & 6.22 & $(0.16)$ & 5.85 & $(0.20)$ & 0.14 & 799 \\
\hline Roof is made of temporary material & 0.38 & $(0.06)$ & 0.26 & $(0.05)$ & 0.00 & 797 \\
\hline Score on math exercise (percent correct) & 0.45 & $(0.03)$ & 0.46 & $(0.03)$ & 0.61 & 816 \\
\hline Keeps formal business accounts & 0.02 & $(0.01)$ & 0.04 & $(0.01)$ & 0.12 & 825 \\
\hline Weekly hours worked in enterprise & 35.91 & $(2.07)$ & 42.18 & (1.41) & 0.02 & 818 \\
\hline Reservation wage, monthly & $2,674.93$ & $(137.15)$ & $3,219.42$ & $(188.06)$ & 0.03 & 656 \\
\hline Maximum loan available if needed & $8,883.73$ & $(3,032.90)$ & $9,378.14$ & $(1,152.20)$ & 0.96 & 651 \\
\hline Monthly interest rate on a potential loan & 6.19 & $(0.45)$ & 6.21 & $(0.35)$ & 0.99 & 479 \\
\hline \multicolumn{7}{|l|}{ Business Characteristics } \\
\hline Produces goods for sale & 0.70 & $(0.04)$ & 0.64 & $(0.03)$ & 0.10 & 827 \\
\hline Last day's profit & 126.03 & (12.11) & 174.10 & $(36.18)$ & 0.21 & 722 \\
\hline Last day's revenue & 378.42 & $(42.16)$ & 456.31 & $(45.64)$ & 0.22 & 793 \\
\hline Number of clients last day & 14.12 & $(1.41)$ & 14.70 & $(1.15)$ & 0.72 & 763 \\
\hline Total number of workers, including owner & 1.57 & $(0.03)$ & 1.75 & $(0.06)$ & 0.02 & 816 \\
\hline Weekly hours worked by employees & 9.22 & $(0.97)$ & 12.45 & (1.39) & 0.04 & 824 \\
\hline Age of business (years) & 6.30 & $(0.71)$ & 8.77 & $(0.71)$ & 0.01 & 826 \\
\hline Replacement value of business capital & $7,875.72$ & $(1,113.79)$ & $10,825.34$ & $(1,137.04)$ & 0.01 & 827 \\
\hline Registered with the government & 0.14 & $(0.03)$ & 0.27 & $(0.03)$ & 0.00 & 800 \\
\hline
\end{tabular}

Notes: Sample includes all subjects interviewed in the baseline survey that did not attrite. A subject "ever quit" if they were not running their business in either the first or second post-treatment survey. Asymptotic robust standard errors in parentheses clustered at the village level; column 5 reflects wild bootstrapped p-values. All monetary variable are measured in Mexican Pesos ( 13 pesos / 1 U.S. dollar). Reservation wage is the minimum stated monthly wage a women would accept in order to quit her business. Government registration is with the Secretary of Finance and Public Credit (SHCP). 
Appendix Table 4: Lee's bounds on the Intention to Treat Effects

\begin{tabular}{|c|c|c|c|c|c|c|}
\hline Outcome: & $\begin{array}{c}\text { Lower Lee } \\
\text { bound on } \\
\text { ITT } \\
\text { (1) }\end{array}$ & $\begin{array}{c}\begin{array}{c}\text { p-value, } \\
\text { Wild } \\
\text { bootstrap }\end{array} \\
(2)\end{array}$ & $\begin{array}{c}\text { Obs. } \\
(3)\end{array}$ & $\begin{array}{c}\text { Upper Lee } \\
\text { bound on } \\
\text { ITT } \\
\text { (4) }\end{array}$ & $\begin{array}{c}\begin{array}{c}\text { p-value, } \\
\text { Wild } \\
\text { bootstrap }\end{array} \\
(5)\end{array}$ & $\frac{\text { Obs. }}{(6)}$ \\
\hline \multicolumn{7}{|l|}{ Main business outcomes } \\
\hline In(Last day's profit) & 0.154 & $(0.242)$ & 1,178 & 0.340 & $(0.010)$ & 1,177 \\
\hline In(Last day's revenue) & 0.165 & $(0.180)$ & 1,349 & 0.359 & $(0.012)$ & 1,350 \\
\hline In(\# clients last day) & 0.145 & $(0.300)$ & 1,305 & 0.337 & $(0.016)$ & 1,301 \\
\hline Standardized & 0.125 & $(0.096)$ & 1,122 & 0.207 & $(0.010)$ & 1,122 \\
\hline \multicolumn{7}{|l|}{ Outcomes calculated from good-specific data } \\
\hline In(Last day's profit) & 0.104 & $(0.702)$ & 832 & 0.313 & $(0.162)$ & 831 \\
\hline In(Last day's revenue) & 0.143 & $(0.310)$ & 1,067 & 0.334 & $(0.116)$ & 1,067 \\
\hline In(\# goods for sale) & 0.024 & $(0.716)$ & 1,415 & 0.432 & $(0.008)$ & 1,380 \\
\hline $\ln ($ Mean unit cost) & -0.361 & $(0.028)$ & 976 & -0.205 & $(0.192)$ & 976 \\
\hline In(Mean unit price) & -0.060 & $(0.284)$ & 1,400 & 0.067 & $(0.300)$ & 1,400 \\
\hline \multicolumn{7}{|l|}{ Other business outcomes } \\
\hline Percent correct on business practices exercise & 0.017 & $(0.792)$ & 1,197 & 0.157 & $(0.052)$ & 1,180 \\
\hline Uses formal accounting methods & -0.025 & (0.078) & 1,419 & 0.940 & $(0.004)$ & 1,266 \\
\hline Number of employees & 0.001 & (0.974) & 1,411 & 0.964 & $(0.026)$ & 1,308 \\
\hline Hours worked per week by owner & -1.283 & $(0.640)$ & 1,396 & 3.705 & $(0.232)$ & 1,403 \\
\hline Hours worked per week by employees & -3.558 & $(0.406)$ & 1,138 & 14.362 & $(0.078)$ & 1,081 \\
\hline Registered with government agency & -0.144 & $(0.006)$ & 1,349 & 0.626 & $(0.000)$ & 1,276 \\
\hline Quit her business & -0.321 & $(0.002)$ & 1,734 & 0.585 & $(0.000)$ & 1,661 \\
\hline
\end{tabular}

Notes: Sample excludes subjects who were not offered treatment in treatment villages. Lower and upper bounds are calculated by first using Lee's methodology to trim each post-intervention period independently, and then estimating our difference in difference model with this trimmed data and the full pre-intervention sample. Covariates included (see text). Wild bootstrap p-values allow for intra-village (cluster) correlation. 